\begin{tabular}{|c|l|}
\hline Title & Fatigue Life A nalysis of Fiber Reinforced Concrete with a Fracture Mechanics Based Model \\
\hline Author(s) & Matsumoto, Takashi \\
\hline Citation & $\begin{array}{l}\text { Cement and Concrete Composites, 21(4), 249-261 } \\
\text { https://doi.org/40.1016/S0958-9465(99)000049 }\end{array}$ \\
\hline Issue Date & 1999-08 \\
\hline Doc URL & http://hdl.handle.net/2115/46777 \\
\hline Type & article (author version) \\
\hline File Information & ccc21_249-261.pdf \\
\hline
\end{tabular}

Instructions for use 


\title{
Fatigue Life Analysis of Fiber Reinforced Concrete with a Fracture Mechanics Based Model
}

\author{
Takashi Matsumoto \\ Department of Civil Engineering, \\ University of Tokyo, 7-3-1 Hongo, Bunkyo-ku, Tokyo 113-8656, Japan \\ and \\ Victor C. Li \\ Advanced Civil Engineering Materials Research Laboratory, \\ Department of Civil and Environmental Engineering, \\ University of Michigan, Ann Arbor, MI 48109-2125, U.S.A.
}

\begin{abstract}
Fatigue life of fiber reinforced concrete (FRC) is theoretically analyzed with a fracture mechanics based model. The model accounts for the effect of cycle-dependent crack bridging properties in FRCs and predicts the number of cycles to failure defined by final fracture subsequent to stable fatigue crack growth in Mode I. The resulting theoretical S-N diagram was compared with experimental data reported in literature. The general agreement supports the validity of the current model, and reveals that cycle-dependent degradation of crack bridging controls fatigue life of FRCs. S-N diagrams are essential for material evaluation and structural design, and the model establishes the link between material structure and S-N diagram in an explicit manner, while the conventional stress-life approach realizes the link in an empirical manner.
\end{abstract}




\section{Introduction}

Development of high fatigue resistant FRCs can contribute to the successful development and maintenance of civil infrastructures. FRCs have been applied to civil infrastructure facilities such as pavements, overlays, bridge deck overlays, railroad sleepers, and industrial floors $1-5$. These facilities have to be maintained in a good service condition, because of their importance to society in many ways, but these facilities may deteriorate due to their exposure to fatigue condition: heavy and frequent loads. Deterioration of highly developed civil infrastructures including these facilities causes serious problems, and maintenance and rehabilitation costs accumulate as civil infrastructures are further developed. To avoid uncontrollable deterioration of civil infrastructures, FRCs are required to be both high in fatigue resistance and low in life-cycle cost so that FRCs can fulfill the expected service life of facilities in a cost efficient manner. Development of high fatigue resistant FRCs has to satisfy the requirements, and this is made feasible when based on the understanding of mechanisms and microstructural parameters that are responsible for fatigue of FRCs.

The development of high fatigue resistant FRCs has relied mainly on an empirical trial and error approach, with experimental determination of an S-N diagram being performed on an FRC beam. S-N diagrams are essential for two reasons: material evaluation and structural design. With an S-N diagram, a new material can be evaluated in comparison to existing materials, and a structure can be designed with allowable stress level under given fatigue life. However, this approach is not efficient due to two disadvantages. First, it requires time-consuming experimental data collection to obtain an S-N diagram. Second, it takes a trial and error approach for the development purpose due to the lack of understanding of mechanisms and microstructural parameters responsible for fatigue of FRCs. These two 
disadvantages should be removed so that the efficient development of high fatigue resistant FRCs can be achieved, while the importance of S-N diagrams is recognized. A theoretical S-N diagram based on the understanding of mechanisms and microstructural parameters responsible for fatigue of FRCs would increase the efficiency of the development.

Theoretical S-N diagrams of FRCs can be generated with a fracture mechanics based model that showed agreement with experimental data in three distinct stages of fatigue crack growth of an FRC ${ }^{6}$. The model predicts the number of cycles to failure which is defined by final failure subsequent to fatigue crack growth, accounting for the effect of cycledependent crack bridging, and it is expressed explicitly in terms of microstructural parameters of FRCs (for example, fiber length, fiber diameter, fiber modulus, fiber volume fraction, and interfacial bond strength). In this paper, the theoretical S-N diagram of four different FRCs has been obtained with the model presented in Li and Matsumoto ${ }^{6}$. It shows that a simple assumption pertaining to the cycle-dependent degradation of crack bridging explains a wide range of experimental results reported in the literature and that the modification of fiber-matrix interface may lead to fatigue life improvement.

\section{Fracture Mechanics Based Fatigue Life Model}

The fracture mechanics based fatigue model of randomly distributed discontinuous fiber composites developed by Li and Matsumoto 6 is summarized in this section. Details of the

model can be found in $\mathrm{Li}$ and Matsumoto ${ }^{6}$, Matsumoto and $\mathrm{Li}{ }^{7}$, and $\mathrm{Wu}$ et al. ${ }^{8}$. The fatigue life model is based on fracture mechanics of fatigue crack growth of FRCs. FRCs fail in fatigue when final unstable fracture takes place subsequent to stable crack growth under fatigue loading. Thus, fatigue life of FRCs is defined by the number of cycles to final failure and, in turn, is controlled by fatigue crack growth behavior. Fatigue crack growth is 
governed by three factors: matrix fatigue crack growth law, crack bridging, and cycledependent degradation of crack bridging (Figure 1). These three factors are reviewed below.

\section{Matrix Fatigue Crack Growth Law}

Matrix fatigue crack growth law for cementitious materials has been observed to obey a Paris law type equation 9-13. Paris law presents the relation between crack growth rate and crack tip stress intensity factor amplitude as

$\frac{\mathrm{da}}{\mathrm{dN}}=\mathrm{C}\left(\Delta \mathrm{K}_{\text {tip }}\right)^{\mathrm{n}}$

where $\mathrm{a}=$ crack length, $\mathrm{N}=$ number of load cycles, $\mathrm{C}=$ Paris constant, $\Delta \mathrm{K}_{\text {tip }}=$ crack tip stress intensity factor amplitude, and $\mathrm{n}=$ Paris constant 14 . Thereby, the current number of load cycles, $\mathrm{N}$, at a given crack length, a, can be obtained by

$$
\mathrm{N}=\int_{\mathrm{a}_{\mathrm{i}}}^{\mathrm{a}} \frac{1}{\mathrm{C}\left(\Delta \mathrm{K}_{\text {tip }}\right)^{\mathrm{n}}} \mathrm{da}
$$

where $a_{i}=$ initial crack length.

Fatigue life, $\mathrm{N}_{\mathrm{f}}$, is defined by final unstable fracture subsequent to fatigue crack growth and is obtained by calculating the number of load cycles spent for growing the crack from the initial length, $a_{i}$, to the final length, $a_{\mathrm{f}}$. This final unstable fracture condition is met when crack tip stress intensity factor surpasses matrix fracture toughness and is simply given by 
$\mathrm{K}_{\max }=\mathrm{K}_{\mathrm{c}}$

where $\mathrm{K}_{\max }=$ crack tip stress intensity factor at maximum load level and $\mathrm{K}_{\mathrm{c}}=$ matrix fracture toughness. $\mathrm{K}_{\max }$ is a function of body geometry, loading mode, crack bridging, and crack configuration, so the condition determines the final crack length, $\mathrm{a}_{\mathrm{f}}$, at fracture failure when other variables are given.

Hence, fatigue life can be computed, if $\Delta \mathrm{K}_{\text {tip }}$ and $\mathrm{K}_{\max }$ are obtained for a given FRC for a given body geometry and loading mode. $\Delta \mathrm{K}_{\text {tip }}$ and $\mathrm{K}_{\max }$ can be determined using similar procedures, and only the steps to obtain $\Delta \mathrm{K}_{\text {tip }}$ are summarized below. The crack tip stress intensity factor amplitude, $\Delta \mathrm{K}_{\text {tip }}$, of FRCs is attributed to external applied loading and crack bridging, so $\Delta \mathrm{K}_{\text {tip }}$ can be decomposed into two parts:

$\Delta \mathrm{K}_{\text {tip }}=\Delta \mathrm{K}_{\mathrm{a}}+\Delta \mathrm{K}_{\mathrm{b}}$

where $\Delta \mathrm{K}_{\mathrm{a}}=$ stress intensity factor amplitude due to external applied loading and $\Delta \mathrm{K}_{\mathrm{b}}=$ stress intensity factor amplitude due to crack bridging. $\Delta \mathrm{K}_{\mathrm{a}}$ for a beam in flexural bending that has a crack on the tension face is given by

$\Delta \mathrm{K}_{\mathrm{a}}=2 \int_{0}^{\mathrm{a}} \mathrm{G}(\mathrm{x}, \mathrm{a}, \mathrm{w}) \Delta \sigma_{\mathrm{a}}(\mathrm{x}) \mathrm{dx}$

where $\mathrm{w}=$ beam depth, $\Delta \sigma_{\mathrm{a}}(\mathrm{x})=\Delta \sigma_{\mathrm{o}}(1-2 \mathrm{x} / \mathrm{w})$ (linear gradient for bending), $\Delta \sigma_{\mathrm{o}}=$ applied external flexural stress amplitude, which is the difference between $\sigma_{\max }=$ maximum stress level and $\sigma_{\min }=$ minimum stress level, and $\mathrm{x}$ is measured from the tension 
face of the beam $15,16 . \mathrm{G}(\mathrm{x}, \mathrm{a}, \mathrm{w})$ is a weight function that represents the contribution of a unit force on the crack surface to the crack tip stress intensity factor and is specific to body geometry and crack configuration 15,16 . Similarly, $\Delta \mathrm{K}_{\mathrm{b}}$ is a function of the relation between the crack bridging stress amplitude, $\Delta \sigma_{\mathrm{b}}$, and the crack opening displacement amplitude, $\Delta \delta$, (hereafter referred to as the cyclic bridging law) and is given by

$$
\Delta \mathrm{K}_{\mathrm{b}}=-2 \int_{0}^{\mathrm{a}} \mathrm{G}(\mathrm{x}, \mathrm{a}, \mathrm{w}) \Delta \sigma_{\mathrm{b}}(\Delta \delta(\mathrm{x})) \mathrm{dx}
$$

where $\Delta \sigma_{\mathrm{b}}(\Delta \delta)=$ cyclic bridging law and $\Delta \delta(\mathrm{x})=$ crack opening displacement amplitude at a point, $x$, on the crack surface.

The computation of $\Delta \mathrm{K}_{\text {tip }}$ and $\mathrm{K}_{\max }$ requires a numerical scheme to solve an integral equation on crack opening displacement amplitude, $\Delta \delta(\mathrm{x})$, and crack opening displacement at maximum load level, $\delta_{\max }(\mathrm{x})$, at a position, $\mathrm{x}$, on the crack surface, respectively. The integral equation on $\Delta \delta(\mathrm{x})$ is given by

$$
\frac{\Delta \delta(\mathrm{x})}{2}=\frac{4}{\mathrm{E}} \int_{\mathrm{x}}^{\mathrm{a}}\left\{\int_{0}^{\mathrm{a}^{\prime}} \mathrm{G}\left(\mathrm{x}^{\prime}, \mathrm{a}^{\prime}, \mathrm{w}\right)\left[\Delta \sigma_{\mathrm{a}}\left(\mathrm{x}^{\prime}\right)-\Delta \sigma_{\mathrm{b}}\left(\Delta \delta\left(\mathrm{x}^{\prime}\right)\right)\right] \mathrm{dx} \mathrm{x}^{\prime}\right\}\left(\mathrm{x}^{\prime}, \mathrm{a}, \mathrm{w}\right) \mathrm{da} \mathrm{a}^{\prime}
$$

This equation is transformed into a matrix equation on $\Delta \delta(\mathrm{x}(\mathrm{i}))$ at grid points, (x(i), $\mathrm{i}=0, \ldots, \mathrm{m})$, where the solution is equivalent to that of the original integral equation with the use of cubic spline integration over the grid points. Details on the numerical scheme can be found in Cox and Marshall 16 . 


\section{Cyclic Bridging law}

Crack bridging in FRCs is exerted by fibers and aggregates. Thus, the cyclic bridging law, $\Delta \sigma_{b}(\Delta \delta)$, is given by the superposition of crack bridging stress-crack opening displacement relation due to fibers and aggregates under cyclic loading:

$\Delta \sigma_{\mathrm{b}}=\Delta \sigma_{\mathrm{f}}+\Delta \sigma_{\mathrm{m}}$

where $\Delta \sigma_{\mathrm{f}}=$ fiber bridging stress change under cyclic loading and $\Delta \sigma_{\mathrm{m}}=$ aggregate bridging stress change under cyclic loading.

Cyclic bridging law due to fibers, $\Delta \sigma_{\mathrm{f}}(\Delta \delta)$, is based on the micromechanics of fiber bridging under cyclic loading. The expression of $\Delta \sigma_{\mathrm{f}}(\Delta \delta)$ is summarized in Appendix I, and more details can be found in $\mathrm{Wu}$ et al. ${ }^{8}$ and Matsumoto and $\mathrm{Li}^{7}$. The normalized cyclic bridging law due to fibers can be represented by

$\Delta \tilde{\sigma}_{\mathrm{f}}=$ function $\left(\Delta \tilde{\delta}, \tilde{\delta}_{\max }, \tilde{\delta}^{*}\right)$

where $\Delta \tilde{\sigma}_{\mathrm{f}}=\Delta \sigma_{\mathrm{f}} / \sigma_{\mathrm{o}}, \sigma_{\mathrm{o}}=\mathrm{V}_{\mathrm{f}} \tau\left(\mathrm{L}_{\mathrm{f}} / \mathrm{d}_{\mathrm{f}}\right) / 2, \mathrm{~V}_{\mathrm{f}}=$ fiber volume fraction, $\tau=$ interfacial frictional bond strength, $\mathrm{L}_{\mathrm{f}}=$ fiber length, $\mathrm{d}_{\mathrm{f}}=$ fiber diameter, $\Delta \tilde{\delta}=\Delta \delta /\left(\mathrm{L}_{\mathrm{f}} / 2\right)$, $\tilde{\delta}_{\max }=\delta_{\max } /\left(\mathrm{L}_{\mathrm{f}} / 2\right), \tilde{\delta}^{*}=\delta^{*} /\left(\mathrm{L}_{\mathrm{f}} / 2\right)=\left(2 \tau \mathrm{L}_{\mathrm{f}}\right) /\left(\mathrm{E}_{\mathrm{f}} \mathrm{d}_{\mathrm{f}}\right)$, and $\mathrm{E}_{\mathrm{f}}=$ fiber modulus. Normalized curves of fiber bridging stress-crack opening displacement relation for a short fiber composite with $\tilde{\delta}^{*}=0.002$ are shown in Figures 2 and 3 for pre-peak and post-peak respectively. 
Monotonic bridging law due to fibers, $\sigma_{\mathrm{f}}(\delta)$, is required, since $\delta_{\max }$ is related to the maximum fiber bridging stress, $\sigma_{\mathrm{f} \max }$, in the preceding load cycle. The expression of $\sigma_{\mathrm{f}}(\delta)$ is summarized in Appendix I, and more details can be found in $\mathrm{Li}^{17}$.

The aggregate bridging law under cyclic and monotonic loading are also required in order to obtain $\Delta \sigma_{\mathrm{b}}$ by superposition. The cyclic bridging law, $\Delta \sigma_{\mathrm{m}}(\Delta \delta)$, is modeled with a simple assumption based on a monotonic bridging law, $\sigma_{\mathrm{m}}(\delta){ }^{18}$. This empirical monotonic bridging law fits a wide range of experimental data. The cyclic bridging law assumes that the aggregate bridging stress, $\sigma_{\mathrm{m}}$, and the crack opening displacement, $\delta$, decrease to zero when unloading takes place. The expressions of $\Delta \sigma_{\mathrm{m}}(\Delta \delta)$ and $\sigma_{\mathrm{m}}(\delta)$ are summarized in Appendix II.

\section{Cycle-Dependent Degradation of Crack Bridging}

Cycle-dependent degradation of crack bridging is shown to exist by experimental observations in fiber reinforced ceramic 19-21, fiber reinforced concrete ${ }^{22}$, and concrete 23 , 24. Degradation of fiber- and aggregate-matrix interface bond is the main mechanism when no fiber or aggregate rupture is observed. Based on this observation, a bilinear degradation function for fiber bridging is suggested by Matsumoto and $\mathrm{Li}^{7}$.

As for the degradation of fiber bridging, the fiber-matrix interfacial frictional bond strength, $\tau$, is assumed to change as follows:

$$
\frac{\tau}{\tau_{\mathrm{i}}}=\max \text { of }\left\{\begin{array}{l}
1.0+\mathrm{D}_{1} \sum_{\mathrm{i}=1}^{\mathrm{N}} \Delta \delta_{\mathrm{i}}(\mathrm{x}) \\
\mathrm{B}+\mathrm{D}_{2} \sum_{\mathrm{i}=1}^{\mathrm{N}} \Delta \delta_{\mathrm{i}}(\mathrm{x})
\end{array}\right.
$$


where $\tau_{\mathrm{i}}=$ initial bond strength, $\mathrm{D}_{1}=$ degradation coefficient for the early trend (negative for degradation), $\Delta \delta_{\mathrm{i}}=$ crack opening displacement change at $\mathrm{i}$-th cycle, $\mathrm{B}=$ intercept for the long trend, and $\mathrm{D}_{2}=$ degradation coefficient for the long trend (negative for degradation). Here, the interfacial bond degradation is measured with

$\sum_{\mathrm{i}=1}^{\mathrm{N}} \Delta \delta_{\mathrm{i}}(\mathrm{x})=$ accumulated crack opening displacement change at $\mathrm{x}$.

where $\mathrm{x}$ is the position on the crack surface. This parameter takes a value related to the number of cycles and the crack opening displacement change experienced at each point on the bridged crack surface. For a growing crack with non-uniform crack profile, the parameter takes the maximum value near the crack mouth and the minimum at the crack tip, meaning that crack bridging degradation is the most severe near the crack mouth and minimal at the crack tip.

Similarly, as for the degradation of aggregate bridging, the current degraded aggregate bridging stress, $\sigma_{\mathrm{m}}$, is scaled to the original undegraded aggregate bridging stress, $\sigma_{\mathrm{m}}$ o, with the accumulated crack opening displacement change, namely

$\frac{\sigma_{\mathrm{m}}}{\sigma_{\mathrm{m} o}}=\max$ of $\left\{\begin{array}{l}1.0+\mathrm{D}_{\mathrm{m} 1} \sum_{\mathrm{i}=1}^{\mathrm{N}} \Delta \delta_{\mathrm{i}}(\mathrm{x}) \\ \mathrm{B}_{\mathrm{m}}+\mathrm{D}_{\mathrm{m} 2} \sum_{\mathrm{i}=1}^{\mathrm{N}} \Delta \delta_{\mathrm{i}}(\mathrm{x})\end{array}\right.$ 
where $D_{m 1}=$ degradation coefficient for the early trend (negative for degradation), $B_{m}=$ intercept for the long trend, and $\mathrm{D}_{\mathrm{m} 2}=$ degradation coefficient for the long trend (negative for degradation).

Total degradation of crack bridging stress is obtained by the superposition of degrading bridging stress due to fibers and aggregates (Figure 4).

\section{Fatigue Life Analysis of FRCs}

Fatigue life of one plain concrete and four different FRCs is simulated with the theoretical model summarized above and is represented in the form of the S-N diagram. A comparison of this theoretical diagram with the experimental one provides confidence in the overall approach of the model. First, the experiment by Zhang and Stang 25 is summarized. Second, the flow of fatigue life computation is explained. Finally, fatigue crack growth is compared between plain concrete and FRCs, and the theoretical diagram is shown and compared with the experimental one.

\section{Experiment}

The fatigue study carried out by Zhang and Stang included one plain concrete and four FRCs (hereafter referred to as PLC, SS1, HS1, HS2, and HYB) ${ }^{25}$. The concrete matrix is made of coarse aggregates of maximum size $8 \mathrm{~mm}$ and fine aggregates of maximum size 4 $\mathrm{mm}$, and fiber volume fraction as shown in Table 1. The beams with depth $100 \mathrm{~mm}$, thickness $50 \mathrm{~mm}$, and length $350 \mathrm{~mm}$ were loaded in three point flexure with a span of 345 $\mathrm{mm}$. In the monotonic flexural loading test, the modulus of rupture $\left(\sigma_{\mathrm{r}}\right)$ of each of the five materials was measured (Table 5). In the cyclic flexural loading test, constant amplitude load was applied, where the maximum load level varied from 75 to $95 \%$ of $\sigma_{\mathrm{r}}$ for PLC and HS2 and from 90 to $95 \%$ for SS1, HS1, and HYB. The minimum load level was always 
$20 \%$ of the maximum $(\mathrm{R}=0.2)$. As a result of cyclic tests, the $\mathrm{S}-\mathrm{N}$ diagram was obtained for the five materials (Figures 16 and 17).

\section{Flow of Fatigue Life Computation}

Flow of the theoretical fatigue life computation consists of two steps and is explained below (Figure 5).

First, analysis is performed to compute the modulus of rupture of each material under monotonic loading. The theoretical model can compute the applied stress at which the crack is about to propagate for a given crack length between the initial flaw size, $a_{0}$, and the beam depth. Thus, the relation between the crack propagation stress and the crack length can be obtained, and this shows the maximum stress sustainable throughout the crack growth under monotonic flexural loading, which is the modulus of rupture of that material. The relation is specific to each material, since crack bridging is dependent on the presence, type, and amount of bridging fibers. The relation also determines the initial size of the fatigue crack, $a_{i}$, in (2). For example, fatigue loading at $80 \%$ of $\sigma_{\mathrm{r}}$ implies that the crack has grown at first loading to its corresponding crack length, $\mathrm{a}_{\mathrm{i}}$, and continues to grow throughout the following cyclic loading (Figure 5).

Second, analysis is performed to compute the fatigue life of each material under cyclic loading. Starting from the initial fatigue crack size, $a_{i}, \Delta K_{\text {tip }}$ and $K_{\max }$ are computed for a crack length, a, under a given constant stress amplitude. With $\Delta \mathrm{K}_{\text {tip }}(\mathrm{a})$ known, $\mathrm{N}(\mathrm{a})$ can be calculated with the use of (2). Crack bridging degradation effect is considered as described in the previous section, and this becomes prominent, as the crack becomes longer and the number of cycles becomes larger. Fatigue life is defined by the number of cycles at which 
the maximum stress intensity factor, $\mathrm{K}_{\max }$, surpasses the matrix fracture toughness, $\mathrm{K}_{\mathrm{c}}$. Physically this means that materials fail when unstable fracture takes place.

\section{Theoretical Analysis}

The monotonic analysis is applied to compute the modulus of rupture of the five materials with microstructural parameters as shown in Tables 1 through 4 . The parameters have been measured independently of this theoretical work, except for matrix fracture toughness and initial flaw size. For all five materials, the matrix fracture toughness is assumed to be 0.5 $\mathrm{MPa} \sqrt{ } \mathrm{m}^{26}$, and the initial flaw size, $\mathrm{a}_{\mathrm{o}}$, is assumed to exist with the size of $3 \mathrm{~mm}$ on the tension face of the beam in order to account for the most severe situation of a flexural beam with a flaw.

Slip-softening relation at the fiber-matrix interface under monotonic loading is used and is assumed to take the simple form

$$
\tau(\delta)= \begin{cases}\tau_{0} & \text { for } \delta \leq \delta^{*} \\ \tau_{0}+a_{1} \delta & \text { for } \delta^{*}<\delta\end{cases}
$$

where $\tau_{\mathrm{o}}=$ initial bond strength and $\mathrm{a}_{1}=$ slip-softening/hardening coefficient (negative for softening). The values of $\tau_{\mathrm{o}}$ and $\mathrm{a}_{1}$ are shown in Table 4. These values for HS1, HS2, and HYB are obtained from experimental evaluations on the same concrete mix, and those for SS1 are chosen based on typically observed values 27,28 .

The resulting theoretical relation between the crack propagation stress and the crack length is shown for all five materials in Figure 6, and the theoretical $\sigma_{\mathrm{r}}$ is summarized in Table 5. 
It is shown that $\sigma_{\mathrm{r}}$ is improved by the addition of fibers and that the crack length at $\sigma_{\mathrm{r}}$ varies from one to another. For example, the $\sigma_{\mathrm{r}}$ of HS2 is exerted at a long crack length $(0.07 \mathrm{~m})$, while the $\sigma_{\mathrm{r}}$ of PLC takes place at a short crack length $(0.006 \mathrm{~m})$. This is because the modulus of rupture of HS2 is mainly attributed to the sustainable stress increase due to crack bridging after first cracking, while the one of PLC relies mainly on the stress increase before first cracking. Other three FRCs (SS1, HS1, and HYB) show similar results, falling between PLC and HS2, and no significant effect of additional $1 \%$ of polypropylene fibers is observed in HYB when compared to the effect of additional $1 \%$ of hooked-end steel fibers in HS2. In the monotonic analysis, the theoretical values of $\sigma_{\mathrm{r}}$ agree well with the experimentally measured ones.

The cyclic analysis needs some additional parameters. First, Paris law constants are needed. These constants have not been well determined for cementitious materials, although experimental investigations have been conducted by four indepedent research groups $9-13$. Paris constant, n, varies from 3.12 to 14.0 for concrete 9,12 and from 2.31 to 4.18 for mortar ${ }^{13}$, depending on mixes and loading condtions. The current analysis assumes that the Paris law constants measured by Baluch et al. ${ }^{9}$ (Table 6) applies to the matrix of FRCs. These Paris law constants were measured under $\mathrm{R}=0.2$ which is the same ratio used in the fatigue experiment by Zhang and Stang ${ }^{25}$, and, with these constants, the cyclic analysis is performed under $\mathrm{R}=\sigma_{\min } / \sigma_{\max }=0.2$.

Second, the degradation coefficients $\left(\mathrm{D}_{1}, \mathrm{D}_{2}\right.$, and $\left.\mathrm{B}\right)$ and $\left(\mathrm{D}_{\mathrm{m} 1}, \mathrm{D}_{\mathrm{m} 2}\right.$, and $\left.\mathrm{B}_{\mathrm{m}}\right)$ are determined as follows (Tables 7 and 8). For the plain concrete, the set of degradation coefficients $\left(D_{m 1}\right.$, $\mathrm{D}_{\mathrm{m} 2}$, and $\mathrm{B}_{\mathrm{m}}$ ) shown in Table 7 is estimated to yield a close agreement with the experimental S-N diagram for plain concrete, and this set of coefficients for aggregate 
bridging is also used for the four FRCs. Thus, two kinds of degrading crack bridging stresses are superposed in the case of FRCs. For the four different FRCs, only one set of interfacial bond degradation coefficients $\left(\mathrm{D}_{1}, \mathrm{D}_{2}\right.$, and $\left.\mathrm{B}\right)$ is used to yield a general agreement with the experimental S-N diagrams of all the FRCs, regardless of the type and amount of fibers in a material. No attempt is made to estimate a set of degradation coefficients for each FRC. This is because there is a lack of experimental data for any of the four FRCs and because, except for the polypropylene fiber, the interface degradation is considered to be on the same order for the same kind of steel fiber-cement matrix interface in both of the smooth and hooked-end steel fiber reinforced concrete.

Although typically observed microstructural parameters are used when they are not available for a given FRC, future experimental investigations are needed for the determination of those parameters in order to perform fatigue crack growth and fatigue life analysis in a more consistent manner.

\section{Results}

Fatigue crack growth behavior of plain concrete and four FRCs is shown in Figures 7 through 11. A theoretical S-N diagram is shown in Figures 16 and 17.

Fatigue crack growth has been observed to show three stages: initial decelerated growth, steady state growth, and final accelerated growth ${ }^{29}$. These three stages are caused by the changes of the total crack tip stress intensity factor amplitude, $\Delta \mathrm{K}_{\text {tip }}$, which is the sum of the positive term, $\Delta \mathrm{K}_{\mathrm{a}}$, and the negative term, $\Delta \mathrm{K}_{\mathrm{b}}$, in (4). $\Delta \mathrm{K}_{\text {tip }}$ decreases when $\left|\Delta \mathrm{K}_{\mathrm{b}}\right|$ increases due to the initial development of the bridging zone, holds a constant value when the increase of $\Delta K_{a}$ due to the crack length increase is balanced with the increase of $\left|\Delta K_{b}\right|$, 
and eventually increases as the crack approaches the specimen boundary (due to rapid increase in $\Delta \mathrm{K}_{\mathrm{a}}$ ). These three changes correspond to the experimentally observed three stages of fatigue crack growth. Then, final failure takes place by unstable crack propagation, whenever the crack tip stress intensity factor at the maximum load level, $\mathrm{K}_{\max }$, reaches the matrix fracture toughness, $\mathrm{K}_{\mathrm{c}}$. Arrows in Figures 7 through 11 represent the final unstable crack propagation at corresponding final crack length.

Fatigue crack growth behavior of plain concrete is distinct from that of other four FRCs (Figure 7). From the monotonic analysis, the initial fatigue crack length, $a_{i}$, is about $3 \mathrm{~mm}$ for all cyclic load amplitudes employed $\left(\mathrm{S}_{\max }=\sigma_{\max } / \sigma_{\mathrm{r}}\right.$ and $\left.\mathrm{R}=\sigma_{\min } / \sigma_{\max }=0.2\right)$, and, from the cyclic analysis, the final fatigue crack length, $\mathrm{a}_{\mathrm{f}}$, ranges between 22 and $54 \mathrm{~mm}$. The fatigue crack development is limited to below $54 \mathrm{~mm}$, nearly the half of the beam depth, and the crack growth is prominent in the final acceleration stage and not significant in the initial deceleration and steady state stage. This is because of the bridging zone size in plain concrete, which is smaller than that of FRCs, becomes fully developed at a shorter crack length. The reduction of the total $\Delta \mathrm{K}_{\text {tip }}$ cannot be expected as the crack continues to elongate further, leading the crack to transit from decelerated crack growth to accelerated crack growth.

Fatigue crack growth behavior of FRCs varies depending on the type of fiber reinforcement and stress level as seen in Figures 8 through 11. However, there are two general trends that discern FRCs from plain concrete. First, longer fatigue cracks develop over the beam depth. The initial crack length, $\mathrm{a}_{\mathrm{i}}$, ranges between 4 and $35 \mathrm{~mm}$ depending on the cracking at different levels of first loading, and the final crack length, $\mathrm{a}_{\mathrm{f}}$, is above $50 \mathrm{~mm}$ for all cases. Second, the initial crack growth deceleration is observed over a large range of initial crack 
length increase. For example, hooked-end steel $2 \% \mathrm{FRC}$ has $\mathrm{a}_{\mathrm{i}}$ ranging between 6 and 35 $\mathrm{mm}$ and $\mathrm{a}_{\mathrm{f}}$ between 63 and $76 \mathrm{~mm}$ (Figure 10). The initial crack growth deceleration is prominent in this FRC. As a result, large fatigue crack development is seen in the initial $10 \%$ of fatigue life. In general, fatigue crack growth curves of FRCs and plain concrete can be classified into three groups in the same way as crack propagation curves under monotonic loading. SS1, HS1, and HYB show a similar fatigue crack growth, while PLC and HS2 show remarkable accelerated and decelerated growth respectively. No significant difference between $1 \%$ steel FRCs (SS1 and HS1) arises, and, again, no singnificant effect of additional $1 \%$ of polypropylene fibers is observed in HYB when compared to the effect of additional $1 \%$ of hooked-end steel fibers in HS2.

The effect of fiber volume fraction increase from 1 to $2 \%$ can be seen in Figures 9 and 10 , and the behavior of fatigue crack growth and crack mouth opening displacement (CMOD) distinctly changes with this additional $1 \%$ of fiber volume fraction. First, the initial crack length, $\mathrm{a}_{\mathrm{i}}$, which is caused by the first load application and from which the fatigue crack starts to elongate is significantly long for HS2. The initial crack length of HS2 ranges from 5 to $36 \mathrm{~mm}$, while that of HS1 ranges from 4 to $12 \mathrm{~mm}$. This happens because HS2 is loaded well above the first cracking load for the maximum load ranging from 50 to $90 \%$ of $\sigma_{\mathrm{r}}$ which is exerted at a long crack length due to the large increase of the sustainable stress after first cracking (Figure 6). Second, the fatigue cracks grow rather steadily throughout the fatigue life in HS2, while, in HS1, they propagate rapidly just before the final failure, and the onset of the final rapid growth can be identified. For example, the fatigue crack length of HS2 at $10 \%$ of its fatigue life, $0.1 \mathrm{~N}_{\mathrm{f}}$, under each $\mathrm{S}_{\max }$ ranges from 29 to $50 \mathrm{~mm}$, while that of HS1 ranges from 13 to $17 \mathrm{~mm}$. This means that HS2 loaded under $\mathrm{S}_{\max }=$ 
$90 \%$ grows the crack from 36 to $50 \mathrm{~mm}$ during $0.1 \mathrm{~N}_{\mathrm{f}}$ and spends the rest of its life, $0.9 \mathrm{~N}_{\mathrm{f}}$, with the fatigue crack longer than $50 \mathrm{~mm}$.

The two differences mentioned above are seen also in Figures 12 and 13 . When the five materials are compared in terms of crack length and mouth opening displacement under the same stress ratio to $\sigma_{\mathrm{r}}\left(\mathrm{S}_{\max }=0.9\right.$ and $\left.\mathrm{R}=0.2\right)$, the crack of HS2 starts as the longest and widest among the five materials and stays so for the most of its fatigue life. However, under the same stress magnitude for all materials $\left(\sigma_{\max }=6.3 \mathrm{MPa}=90 \%\right.$ of plain concrete's $\sigma_{\mathrm{r}}$ and $\mathrm{R}=0.2$ ), the crack of HS2 is certainly the shortest and narrowest throughout the fatigue life, while providing the longest fatigue life (Figures 14 and 15). This comparison between two different fiber volume fractions implies that high stress ratio application has to be limited by an acceptable value of CMOD under service conditions, when high strength FRCs are utilized for higher loads than plain concrete. This is due to the fact that increased environmental attacks are expected for a wider crack $30-32$. Details of CMOD analysis can be found elsewhere 33 .

The theoretical S-N diagrams in Figures 16 and 17 can be readily constructed with the number of cycles to failure shown in Figures 7 through 11 and are compared to the experimental S-N diagrams.

The theoretical results agree well with the experimental ones for two materials: plain concrete and hooked-end steel $2 \%$ FRC. The theoretical fatigue life for plain concrete agrees with the experimentally measured life at three of the higher load levels $(90,80$, and $70 \%$ of $\sigma_{\mathrm{r}}$ ), with deviation at the lower load levels (60 and $50 \%$ ). Similarly, the theoretical fatigue life for hooked-end steel $2 \%$ FRC agrees with the experimentally measured life at 
two load levels ( 80 and $75 \%$ of $\sigma_{\mathrm{r}}$ ), although the theoretical S-N relation deviates from experimental data for the higher (90\%) and lower (60 and $50 \%$ ) load levels. However, the theoretical S-N relation for other three FRCs (SS1, HS1, and HYB) deviates far from the correponding experimental data. While the theoretical relation shows the fatigue strength decline to $50 \%$ of $\sigma_{\mathrm{r}}$ at $5 \sim 710^{5}$ cycles, experimental data shows that the fatigue strength is about $90 \%$ of $\sigma_{\mathrm{r}}$ at $10^{6}$ cycles.

Two salient discrepancies are noted in comparison of theoretical results with experimental data. First, the theoretical S-N relation of plain concrete and hooked-end steel $2 \%$ FRC is somewhat deviant from the straight line curve fit to experimental data. Second, the theoretical S-N relation of the other three FRCs does not agree with the curve fitting result.

The first discrepancy may arise because of either one of the following two reasons. First, the assumption of Paris law for crack growth rate may not be correct near the upper and lower limit. Crack growth rate is very high near the upper limit of matrix fracture toughness, $K_{c}$, while it is negligible near the lower limit of fatigue threshold, $\Delta K_{\text {th }}$. Experimentally, fast crack growth has been observed in plain concrete when the maximum level of cyclic loading is half of $\sigma_{\mathrm{r}}$, and no crack growth at one fourth ${ }^{9}$. This correction would decrease the fatigue life at high load level and increase it at low load level, resulting in a theoretical S-N relation closer to the straight line curve fit to experimental data. Second, the assumed functions of crack bridging degradation, (10) and (12), may not be accurate enough for various load levels, since the current function does not take into account the effect of initial crack opening displacement which is different for a different load level. This means that there is no distinction between a large number of small opening changes and a small number of large opening changes, when both cases amount to the same 
accumulated crack opening displacement change. This correction would again increase the fatigue life at low load level. Despite the fact that these two reasons are plausible, whether or not the S-N relation is a straight line on a semi log plot remains a question. The S-N relation has to be determined experimentally with statistically enough number of data points and with accurate representation in a mathematical form.

The second significant discrepancy may be explained as follows. In the S-N diagram, there is a lack of experimental data for lower load levels. The experimental fatigue life for the three FRCs is measured at 90 95\% of $\sigma_{\mathrm{r}}$. As a result, the fatigue life measurement can be easily distributed over a broad range, since this high load level is within the variability range of $\sigma_{\mathrm{r}}$ (see data on y-axis in Figure 16). This leads to the seemingly high fatigue strength mentioned above for the three FRCs, which is contrary to the theoretical fatigue strength. Also, fatigue strength of FRCs has been reported to be within $40 \sim 70 \%$ of $\sigma_{\mathrm{r}}{ }^{34-}$ 38 , and there is only one report for above $90 \%$ of $\sigma_{\mathrm{r}} 39$. The two corrections for the first discrepancy apply here as well, and again the S-N relation needs to be determined for lower load levels with statistical confidence in order to make fair comparisons. It should be noted that the current theoretical model applies to any given FRC with friction controlled fibermatrix interface, if all the microstructural parameters shown in Tables 1 through 4 and 6 through 8 are available for the model. These microstructural parameters for the five materials in this study are typically observed values that have been obtained from several independent measurements by other researchers $9,22,25,27,28$ and used in the theoretical analysis. 


\section{Conclusions}

Fatigue crack growth for plain concrete and four different FRCs has been simulated with a fracture mechanics based model. The four FRCs show that long fatigue cracks develop over the beam depth at final failure and that their initial crack growth is decelerated over a large range of initial crack length increase. These two differences discern the behavior of FRCs from plain concrete. Furthermore, under the same stress ratio, it is shown that, compared to hooked-end steel $1 \%$ FRC, hooked-end steel $2 \%$ FRC shows a less catastrophic failure with slower crack growth towards the final failure, but that it develops a longer and wider fatigue crack in the beginning of the fatigue life. This implies that high stress ratio application to a high fiber volume FRC should be limited by an acceptable CMOD value under service conditions in order to minimize environmental damage resulting due to cracking.

Theoretical S-N diagrams have been made for the five materials and compared with experimental S-N diagrams. The theoretical results agree well with the experimental ones for plain concrete and hooked-end steel $2 \%$ FRC, while they do not agree with that for smooth steel $1 \%$ FRC, hooked-end steel $1 \%$ FRC, and hooked-end $1 \%$ + polypropylene $1 \%$ FRC. The disagreement could be possibly removed by refining the three aspects of crack bridging degradation function. First, crack bridging degradation could be different for steel and polypropylene fiber. Steel fibers suffer from interfacial bond degradation, while polymeric fibers could be subjected to fiber fatigue rupture. Second, among steel fibers, a different set of degradation coefficients is appropriate depending on the combination of fiber and matrix. Third, for both of above two aspects, the function of crack bridging degradation has to be dependent on initial crack opening displacement as well. An increase in the knowledge on fatigue life of FRCs may be attained with further 
refinement of the theoretical model, in conjunction with more accurate experimental S-N diagrams.

Crack growth of plain concrete and four FRCs under monotonic loading has been analyzed in conjuction with fatigue crack growth. The resulting relations between crack propagation stress and crack length yield a close prediction on the modulus of rupture for five materials, and it also indicates the crucial role of bridging zone developement in the crack wake under monotonic and cyclic loading.

The theoretical results show that a single set of degradation parameters explains qualitatively a wide range of experimental fatigue life data. Further, improvement of fatigue life of FRCs necessitates a focus on the fiber-matrix interface degradation. Degradation of crack bridging has to be minimized with the understanding of degradation mechanisms. Such an experimental study can be executed effectively in conjunction with the theoretical analysis presented in this paper in order to contribute to the efficient development of high fatigue resistant FRC.

\section{Acknowledgment}

This work has been supported by a grant from the National Science Foundation (MSS9301949) to the ACE-MRL at the University of Michigan, and by a NATO grant (930023) which supports collaboration research between the ACE-MRL and the Technical University of Denmark. Helpful discussions with Dr. B. N. Cox, Dr. H. Stang, and Dr. J. Zhang are gratefully acknowledged. We are indebted to Dr. B. N. Cox for providing us a numerical code for solving bridged crack problems, and to Dr. H. Stang for providing us unpublished experimental data. 


\section{References}

1. Rizkalla, S. H. \& Mufti, A. A., Recent Innovation for Concrete Highway Bridges. In Proc. ASCE 4th Materials Engineering Conference, ed. K. P. Chong, 1996, pp. 1063-1071.

2. Shirazi, H. H., Rasoulian, M., \& King, B., Design and Construction of a Bonded Fiber Concrete Overlay of CRCP. In Proc. ASCE 4th Materials Engineering Conference, ed. K. P. Chong, 1996, pp. 1647-1658.

3. Strand, D., MacDonald, C. N., Ramakrishnan, V., \& Rajpathak, V. N., Construction Applications of Polyolefin Fiber Reinforced Concrete. In Proc. ASCE 4th Materials Engineering Conference, ed. K. P. Chong, 1996, pp. 103-112.

4. Krstulovic-Opara, N., Haghayeghi, A. R., Haidar, M., \& Krauss, P. D., Use of Conventional and High-Performance Steel-Fiber Reinforced Concrete for Bridge Deck Overlays. ACI Materials Journal, 92(6) (1995) 669-677.

5. Balaguru, P. N. \& Shah, S. P., Fiber-Reinforced Cement Composites. McGraw-Hill Inc., 1992.

6. Li, V. C. \& Matsumoto, T., Fatigue Crack Growth Analysis of Fiber Reinforced Concrete with Effect of Interfacial Bond Degradation. Journal of Cement and Concrete Composites, 20(5) (1998) 339-351.

7. Matsumoto, T. \& Li, V. C., Uniaxial Cyclic Behavior of Discontinuous Fiber Reinforced Composites. In Proc. ASCE 4th Materials Engineering Conference, ed. K. P. Chong, 1996, pp. 426-435. 
8. Wu, H. C., Matsumoto, T., \& Li, V. C., Buckling of Bridging Fibres in Composites. Journal of Materials Science Letters, 13 (1994) 1800-1803.

9. Baluch, M. H., Qureshy, A. B., \& Azad, A. K., Fatigue Crack Propagation in Plain Concrete. In Proc. SEM/RILEM International Conference on Fracture of Concrete and Rock, eds. S. P. Shah and S. E. Swartz, 1987, pp. 80-87.

10. Bazant, Z. P. \& Xu, K., Size Effect in Fatigue Fracture of Concrete. ACI Materials Journal, 88(4) (1991) 390-399.

11. Bazant, Z. P. \& Schell, W. F., Fatigue Fracture of High-Strength Concrete and Size Effect. ACI Materials Journal, 90(5) (1993) 472-478.

12. Perdikaris, P. C. \& Calomino, A. M., Kinetics of Crack Growth in Plain Concrete. In Proc. SEM/RILEM International Conference on Fracture of Concrete and Rock, eds. S. P. Shah and S. E. Swartz, 1987, pp. 64-69.

13. Toumi, A., Bascoul, A., \& Turatsinze, A., Crack Progapation in Concrete Subjected to Flexural-Cyclic Loading. Materials and Structures, 31 (1998) 451-458.

14. Paris, P. C. \& Erdogan, F., A Critical Analysis of Crack Propagation Laws. Journal of Basic Engineering, 85 (1963) 528-534.

15. Tada, H., The Stress Analysis of Cracks Handbook. Paris Prod. Inc., 1985.

16. Cox, B. N. \& Marshall, D. B., Stable and Unstable Solutions for Bridged Cracks in Various Specimens. Acta Metallurgica et Materialia, 39(4) (1991) 579-589. 
17. Li, V. C., Postcrack Scaling Relations for Fiber Reinforced Cementitious Composites. Journal of Materials in Civil Engineering, 4(1) (1992) 41-57.

18. Stang, H., Evaluation of Properties of Cementitious Fiber Composite Materials. In Proc. International RILEM/ACI Workshop, High Performance Fiber Cement Composites, eds. H. W. Reinhardt and A. E. Naaman, 1992, pp. 388-406.

19. Evans, A. G., Zok, F. W., \& McMeeking, R. M., Fatigue of Ceramic Matrix Composites. Acta Metallurgica et Materialia, 43(3) (1995) 859-875.

20. Zok, F. W., McNulty, J., Du, Z. Z., \& Evans, A. G., Effects of Interfacial Wear on Fatigue Failure in Fiber Reinforced CMCs. In Proc. International Conference on Composites Engineering-ICCE/1, 1994, pp. 597-598.

21. Evans, A. G., Design and Life Prediction Issues for High-Temperature Engineering Ceramics and Their Composites. Acta Materialia, 45(1) (1997) 23-40.

22. Zhang, J. \& Stang, H., Experimental Study on Bridging Stress of Fiber Reinforced Concrete under Uniaxial Fatigue Tensile Load. (1997) in preparation.

23. Hordijk, D. A. \& Reinhardt, H. W., Growth of Discrete Cracks in Concrete under Fatigue Loading. In Proc. NATO Advanced Research Workshop-Toughening Mechanisms in Quasi-Brittle Materials, ed. S. P. Shah, 1990, pp. 553-568.

24. Reinhardt, H. W., Cornelissen, H. A. W., \& Hordijk, D. A., Tensile Tests and Failure Analysis of Concrete. Journal of Structural Engineering, 112(11) (1986) $2462-2477$. 
25. Zhang, J. \& Stang, H., Fatigue Performance in Flexure of Fiber Reinforced Concrete. Accepted for publication in ACI Materials Journal, (1996).

26. Li, V. C., Mishra, D. K., \& Wu, H. C., Matrix Design for Pseudo-Strain-Hardening Fibre Reinforced Cementitious Composites. Materials and Structures, 28 (1995) 586-595.

27. Li, V. C. \& Stang, H., Interface Property Characterization and Strengthening Mechanisms in Fiber Reinforced Cement Based Composites. Journal of Advanced Cement Based Composites, 6(1) (1997) 1-20.

28. Li, V. C., Stang, H., \& Krenchel, H., Micromechanics of Crack Bridging in Fiber Reinforced Concrete. Materials and Structures, 26 (1993) 486-494.

29. Stang, H. \& Zhang, J., Experimental Determination of Fatigue Crack Growth in Fiber Reinforced Concrete. In Recent Advances in Experimental Mechanics, ed. J. F. Silva Gomez et al., 1994, pp. 1347-1352.

30. Li, V. C., Performance Driven Design of Fiber Reinforced Cementitious Composites. In Proc. 4th RILEM International Symposium on Fiber Reinforced Concrete, ed. R. N. Swamy, 1992, pp. 12-30.

31. Keer, J. G., Xu, G., \& Filip, R., Cracking and Moisture Penetration in Fibre Cement Sheeting. In Fibre Reinforced Cements and Concretes-Recent Developments, eds. R. N. Swamy and B. Barr, 1989, pp. 592-601.

32. Tsukamoto, T., Tightness of Fiber Concrete. In Darmstadt Concrete, 5, 1990, pp. 215-225. 
33. Matsumoto, T., Fracture Mechanics Approach to Fatigue Life of Discontinuous Fiber Reinforced Composites. Ph. D Thesis, The University of Michigan, Ann Arbor, 1998,

34. Butler, J. E., The Performance of Concrete Containing High Proportions of Steel Fibres with Particular Reference to Rapid Flexural and Fatigue Loadings. In Fiber Reinforced Cements and Concretes-Recent Developments, eds. R. N. Swamy and B. Barr, 1989, pp. 544-552.

35. Wu, G. Y., Shivaraj, S. K., \& Ramakrishnan, V., Flexural, Fatigue Strength, Endurance Limit, and Impact Strength of Fiber Reinforced Refractory Concretes. In Fiber Reinforced Cements and Concretes-Recent Developments, eds. R. N. Swamy and B. Barr, 1989, pp. 261-273.

36. Vondran, G. L., Nagabhushanam, M., \& Ramakrishnan, V., Fatigue Strength of Polypropylene Fiber Reinforced Concretes. In Fiber Reinforced Cements and Concretes-Recent Developments, eds. R. N. Swamy and B. Barr, 1989, pp. 533-543.

37. Ramakrishnan, V., Gollapudi, S., \& Zellers, R., Performance Characteristics and Fatigue Strength of Polypropylene Fiber Reinforced Concrete. In Fiber Reinforced Concrete Properties and Applications SP-105, 1987, pp. 159-177.

38. Ramakrishnan, V. \& Lokvik, B. J., Flexural Fatigue Strength of Fiber Reinforced Concretes. In High Performance Fiber Reinforced Cement Composites, eds. H. W. Reinhardt and A. E. Naaman, 1992, pp. 271-287. 
39. Ramakrishnan, V. \& Josifek, C., Performance Characteristics and Flexural Fatigue Strength of Concrete Steel Fiber Composites. In Proc. International Symposium on Fiber Reinforced Concrete, 1987, pp. 2.73-2.84.

40. Matsumoto, T. \& Li, V. C., Crack Bridging in Discontinuous Fiber Reinforced Composites under Cyclic Loading. (1997) in preparation.

41. Horii, H. \& Okui, Y., Thermomechanics and Micromechanics-Based Continuum Theory for Localization Phenomena. In Proc. International Union of Theoretical and Applied Mechanics (IUTAM) Symposium on Fracture of Brittle, Disordered Materials: Concrete, Rock and Ceramics, eds. G. Baker and B. L. Karihaloo, 1993, pp. 391-405. 


\section{Appendix I: Monotonic and Cyclic Fiber Bridging Law}

Monotonic fiber bridging law

The monotonic fiber bridging law, $\sigma_{\mathrm{f}}(\delta)$, is given in a normalized form derived by $\mathrm{Li} 17$. For pre-peak part,

$\tilde{\sigma}_{\mathrm{f}}(\tilde{\delta})=\mathrm{g}\left[2\left(\frac{\tilde{\delta}}{\tilde{\delta}^{*}}\right)^{\frac{1}{2}}-\left(\frac{\tilde{\delta}}{\tilde{\delta}^{*}}\right)\right\rfloor \quad$ for $0 \leq \tilde{\delta} \leq \tilde{\delta}^{*}$

where $\tilde{\sigma}_{\mathrm{f}}=\sigma_{\mathrm{f}} / \sigma_{\mathrm{o}}, \sigma_{\mathrm{o}}=\mathrm{V}_{\mathrm{f}} \tau\left(\mathrm{L}_{\mathrm{f}} / \mathrm{d}_{\mathrm{f}}\right) / 2, \mathrm{~V}_{\mathrm{f}}=$ fiber volume fraction, $\tau=$ interfacial frictional bond strength, $L_{f}=$ fiber length, $d_{f}=$ fiber diameter, $g=2 /\left(4+f^{2}\right)\left(1+e^{\pi f / 2}\right), f=$ snubbing coefficient, $\tilde{\delta}=\delta /\left(\mathrm{L}_{\mathrm{f}} / 2\right), \tilde{\delta}^{*}=\delta^{*} /\left(\mathrm{L}_{\mathrm{f}} / 2\right)=\left(2 \tau \mathrm{L}_{\mathrm{f}}\right) /\left(\mathrm{E}_{\mathrm{f}} \mathrm{d}_{\mathrm{f}}\right)$, and $\mathrm{E}_{\mathrm{f}}=$ fiber modulus.

For post-peak part,

$$
\tilde{\sigma}_{\mathrm{f}}(\hat{\delta})=\mathrm{g}\left[1-\left(\tilde{\delta}-\tilde{\delta}^{*}\right)\right] \quad \text { for } \tilde{\delta}^{*}<\tilde{\delta} \leq 1
$$

Cyclic fiber bridging law

The cyclic fiber bridging law, $\Delta \sigma_{\mathrm{f}}(\Delta \delta)$, was modeled by Matsumoto and $\mathrm{Li} 40$ and is given in a normalized form by

$$
\Delta \tilde{\sigma}_{\mathrm{f}}(\Delta \tilde{\delta})= \begin{cases}\left.\Delta \tilde{\sigma}_{\mathrm{f}}\right|_{\text {prepeak }} & \left(\text { for } 0 \leq \tilde{\delta} \leq \tilde{\delta}^{*}\right) \\ \left.\Delta \tilde{\sigma}_{\mathrm{f}}\right|_{\text {postpeak }} & \left(\text { for } \tilde{\delta}^{*}<\tilde{\delta} \leq 1\right)\end{cases}
$$


where $\Delta \tilde{\sigma}_{\mathrm{f}}=\Delta \sigma_{\mathrm{f}} / \sigma_{\mathrm{o}}$ and $\Delta \tilde{\delta}=\Delta \delta /\left(\mathrm{L}_{\mathrm{f}} / 2\right)$.

For pre-peak part,

$\left.\left.\Delta \tilde{\sigma}_{\mathrm{f}}\right|_{\text {prepeak }}=\mathrm{g} 2 \sqrt{2}\left(\frac{\Delta \tilde{\delta}}{\tilde{\delta}^{*}}\right)^{\frac{1}{2}}\left(1-\tilde{\delta}_{\text {max }}\right)-\frac{\Delta \tilde{\delta}}{\tilde{\delta}^{*}}+\sqrt{2}\left(\frac{\Delta \tilde{\delta}}{\tilde{\delta}^{*}}\right)^{\frac{3}{2}} \tilde{\delta}^{*}-\frac{1}{2}(\Delta \tilde{\delta})^{2}\right\rceil$

where $\tilde{\delta}_{\max }=\delta_{\max } /\left(\mathrm{L}_{\mathrm{f}} / 2\right)$ and $\delta_{\max }=$ maximum crack opening displacement experienced in the preceding load cycle.

For post-peak part, there are two stages. When only some fibers are in sliding back into matrix $\left(\beta \leq \beta_{0}\right)$, the bridging law, $\left.\Delta \tilde{\sigma}_{\mathrm{f}}\right|_{\text {postpeak }}$, is the same as that of pre-peak part and is given by (I 4) for $\beta \leq \beta_{\mathrm{o}}$ where $\beta=\Delta \tilde{\delta} / \tilde{\delta}_{\max }$ and

$\beta_{\mathrm{o}}=\left|\frac{\left.\mid \sqrt{\frac{\tilde{\delta}_{\max }}{2 \tilde{\delta}^{*}}}-\sqrt{\frac{\tilde{\delta}_{\max }}{2 \tilde{\delta}^{*}}-2 \tilde{\delta}_{\max }\left(1-\tilde{\delta}_{\max }\right)}\right)^{2}}{\tilde{\delta}_{\max }}\right|$.

When all fibers are in sliding back into matrix, the bridging law, $\left.\Delta \tilde{\sigma}_{\mathrm{f}}\right|_{\text {postpeak }}$, is given by

$\left.\Delta \tilde{\sigma}_{\mathrm{f}}\right|_{\text {postpeak }}=\mathrm{g}\left[2\left(1-\tilde{\delta}_{\max }\right)\left(1-\tilde{\delta}_{\max }+\Delta \tilde{\delta}\right)\right] . \quad$ for $\beta_{\mathrm{o}}<\beta$ 


\section{Appendix II: Monotonic and Cyclic Aggregate Bridging Law}

The monotonic aggregate bridging law is given by an empirical equation proposed by Stang 18. The aggregate bridging stress, $\sigma_{\mathrm{m}}$, as a function of the crack opening displacement, $\delta$, is given by

$$
\sigma_{\mathrm{m}}(\delta)=\frac{\sigma_{\mathrm{m}}^{\mathrm{u}}}{1+\left(\frac{\delta}{\delta_{\mathrm{o}}}\right)^{\mathrm{p}}}
$$

where $\sigma_{\mathrm{m}}^{\mathrm{u}}=$ maximum aggregate bridging stress at $\delta=0, \delta_{\mathrm{o}}=$ crack opening displacement which corresponds to the half of $\sigma_{\mathrm{m}}^{\mathrm{u}}$, and $\mathrm{p}$ describes the shape of the bridging curve.

The cyclic aggregate bridging law follows a typical formulation where stress and strain return to the origin upon unloading 41 , and this is simply given by

$$
\Delta \sigma_{\mathrm{m}}(\Delta \delta)=\frac{\sigma_{\mathrm{m} \max }}{\delta_{\max }} \Delta \delta
$$

where $\left(\delta_{\max }, \sigma_{\mathrm{m} \max }\right)$ is the point at which unloading occurs. 


\section{Figure Captions}

Figure 1 Fatigue damage on material constituents.

Figure 2 Fiber bridging stress-crack opening displacement (COD) relation (bridging law) for pre-peak. ${ }^{7}$

Figure 3 Fiber bridging stress-crack opening displacement (COD) relation (bridging law) for post-peak. ${ }^{7}$

Figure 4 Crack bridging degradation assumed in the current fatigue life analysis.

Figure 5 Flow of monotonic and cyclic analysis.

Figure 6 Monotonic analysis: crack length vs. equilibrium flexural stress.

Figure 7 Fatigue crack growth in plain concrete (PLC).

Figure 8 Fatigue crack growth in smooth steel $1 \%$ FRC (SS1).

Figure 9 Fatigue crack growth in hooked-end steel $1 \%$ FRC (HS1).

Figure 10 Fatigue crack growth in hooked-end steel $2 \%$ FRC (HS2). 
Figure 11 Fatigue crack growth in hooked-end steel $1 \%+$ polypropylene $1 \%$ FRC (HYB).

Figure 12 Fatigue crack growth behavior of plain concrete and four FRCs under $\mathrm{S}_{\max }=$ $90 \%$ and $\mathrm{R}=0.2$.

Figure 13 CMOD behavior of plain concrete and four FRCs under $\mathrm{S}_{\max }=90 \%$ and $\mathrm{R}=0.2$.

Figure 14 Fatigue crack growth behavior of plain concrete and four FRCs under $\Delta \sigma=5.0$ $\mathrm{MPa}$ and $\mathrm{R}=0.2$.

Figure 15 CMOD behavior of plain concrete and four FRCs under $\Delta \sigma=5.0 \mathrm{MPa}$ and $\mathrm{R}=$ 0.2 .

Figure 16 Theoretical S-N diagram and experimental data 25 of plain concrete and four FRCs.

Figure 17 Theoretical S-N diagram and curve fit to experimental data 25 of plain concrete and four FRCs. 
Table 1 Mix compositions. 25

\begin{tabular}{llllll}
\hline & PLC & SS1 & HS1 & HS2 & HYB \\
\hline Smooth steel $\mathrm{V}_{\mathrm{f}}(\%)$ & 0 & 1 & 0 & 0 & 0 \\
Hooked-end steel $\mathrm{V}_{\mathrm{f}}(\%)$ & 0 & 0 & 1 & 2 & 1 \\
Polypropylene $\mathrm{V}_{\mathrm{f}}(\%)$ & 0 & 0 & 0 & 0 & 1 \\
\hline
\end{tabular}

Table 2 Fiber parameters. 25

\begin{tabular}{llll}
\hline Fiber & $\mathrm{d}_{\mathrm{f}}(\mu \mathrm{m})$ & $\mathrm{L}_{\mathrm{f}}(\mathrm{mm})$ & $\mathrm{E}_{\mathrm{f}}(\mathrm{GPa})$ \\
\hline Smooth steel & 400 & 25 & 210 \\
Hooked-end steel & 500 & 30 & 210 \\
Polypropylene & 48 & 12 & 12 \\
\hline
\end{tabular}

Table 3 Matrix parameters. 22 (*: assumed value)

\begin{tabular}{llllll}
\hline Matrix & $\mathrm{E}_{\mathrm{m}}(\mathrm{GPa})$ & $\sigma_{\mathrm{m}}^{\mathrm{u}}(\mathrm{MPa})$ & $\mathrm{p}$ & $\delta_{\mathrm{o}}(\mathrm{mm})$ & $\mathrm{K}_{\mathrm{c}}(\mathrm{MPa} \sqrt{\mathrm{m}})$ \\
\hline & 55 & 5.4 & 1.2 & 0.015 & $0.5^{*}$ \\
\hline
\end{tabular}


Table 4 Interface parameters. 27,28

\begin{tabular}{lcccl}
\hline Interface & SS1 & HS1 & HS2 & HYB \\
\hline$\tau_{\mathrm{o}}(\mathrm{MPa})$ & 6.0 & 4.5 & 4.5 & $4.5+0.8$ \\
$\mathrm{a}_{1}(\mathrm{MPa} / \mathrm{mm})$ & -4.0 & -2.0 & -2.0 & $-2.0+0.0$ \\
$\mathrm{f}$ & 0.8 & 0.75 & 0.75 & $0.75+0.0$ \\
\hline
\end{tabular}

Table 5 Experimental and theoretical $\sigma_{\mathrm{r}}$.

\begin{tabular}{lccccc}
\hline & PLC & SS1 & HS1 & HS2 & HYB \\
\hline Experimental $\sigma_{\mathrm{r}} 25(\mathrm{MPa})$ & 6.94 & 10.15 & 8.88 & 12.82 & 9.46 \\
Theoretical $\sigma_{\mathrm{r}}(\mathrm{MPa})$ & 7.02 & 10.43 & 8.95 & 12.9 & 9.83 \\
\hline
\end{tabular}

Table 6 Paris law constants. 9

\begin{tabular}{lll}
\hline Paris constant & $\mathrm{C}$ & $\mathrm{n}$ \\
\hline & $9.0310^{-6}$ & 3.12 \\
\hline
\end{tabular}

Table 7 Degradation coefficients for aggregate bridging.

\begin{tabular}{ll}
\hline & PLC \\
\hline $\mathrm{D}_{\mathrm{m} 1}(/ \mathrm{mm})$ & -0.6 \\
$\mathrm{D}_{\mathrm{m} 2}(/ \mathrm{mm})$ & -0.001 \\
$\mathrm{~B}_{\mathrm{m}}$ & 0.7 \\
\hline
\end{tabular}


Table 8 Degradation coefficients for interface bond strength.

\begin{tabular}{|c|c|c|c|c|c|}
\hline & SS1 & HS1 & HS2 & $\begin{array}{l}\text { HYB } \\
\text { (hooked-end } \\
\text { polypropylene) }\end{array}$ & steel, \\
\hline $\mathrm{D}_{1}(/ \mathrm{mm})$ & -0.003 & -0.003 & -0.003 & $-0.003,-0.003$ & \\
\hline $\mathrm{D}_{2}(/ \mathrm{mm})$ & -0.00003 & -0.00003 & -0.00003 & $-0.00003,-0.00003$ & \\
\hline B & 0.8 & 0.8 & 0.8 & $0.8,0.8$ & \\
\hline
\end{tabular}




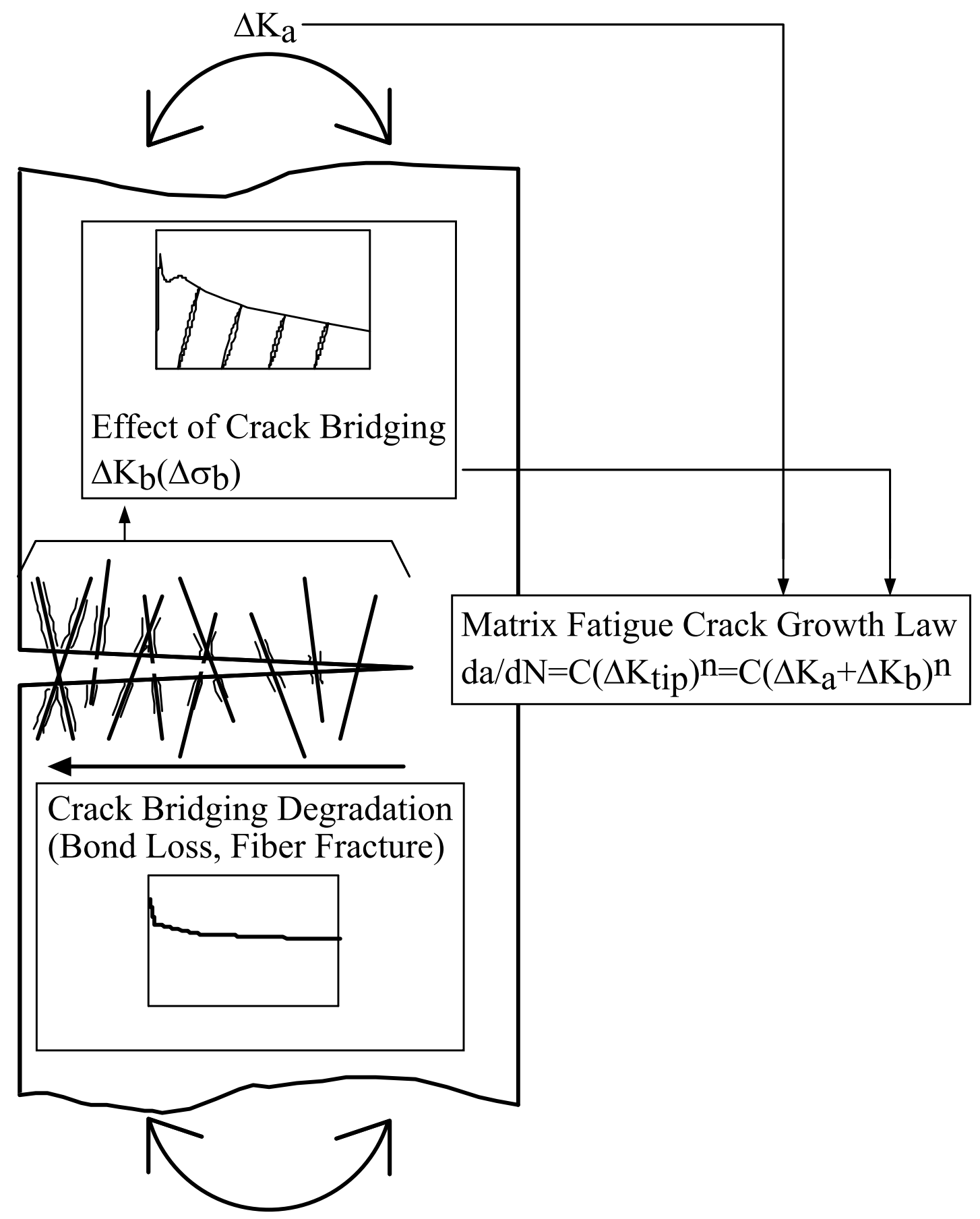

Figure 1 Fatigue damage on material constituents. 


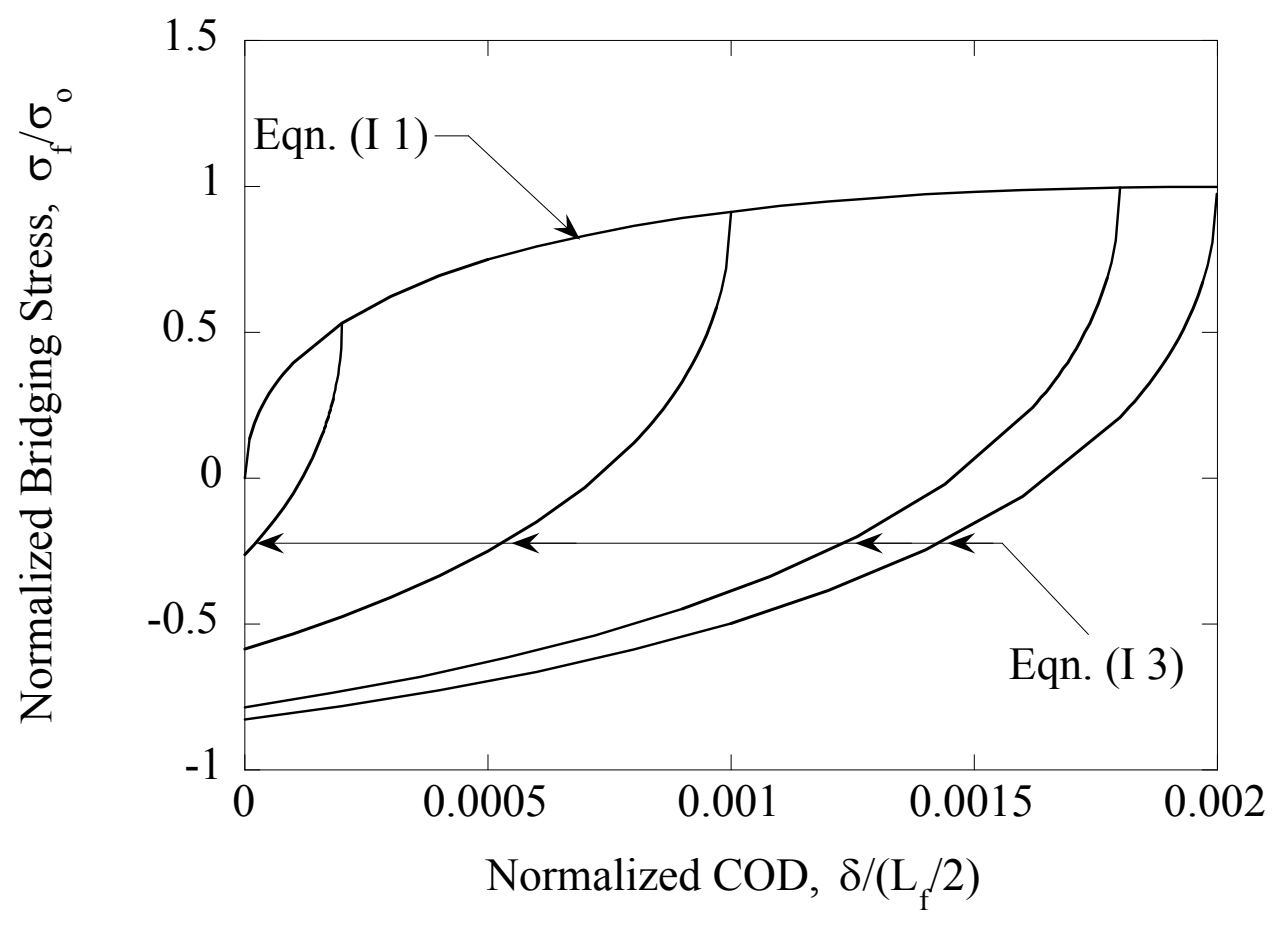

Figure 2 Fiber bridging stress-crack opening displacement (COD) relation (bridging law) for pre-peak. ${ }^{7}$ 


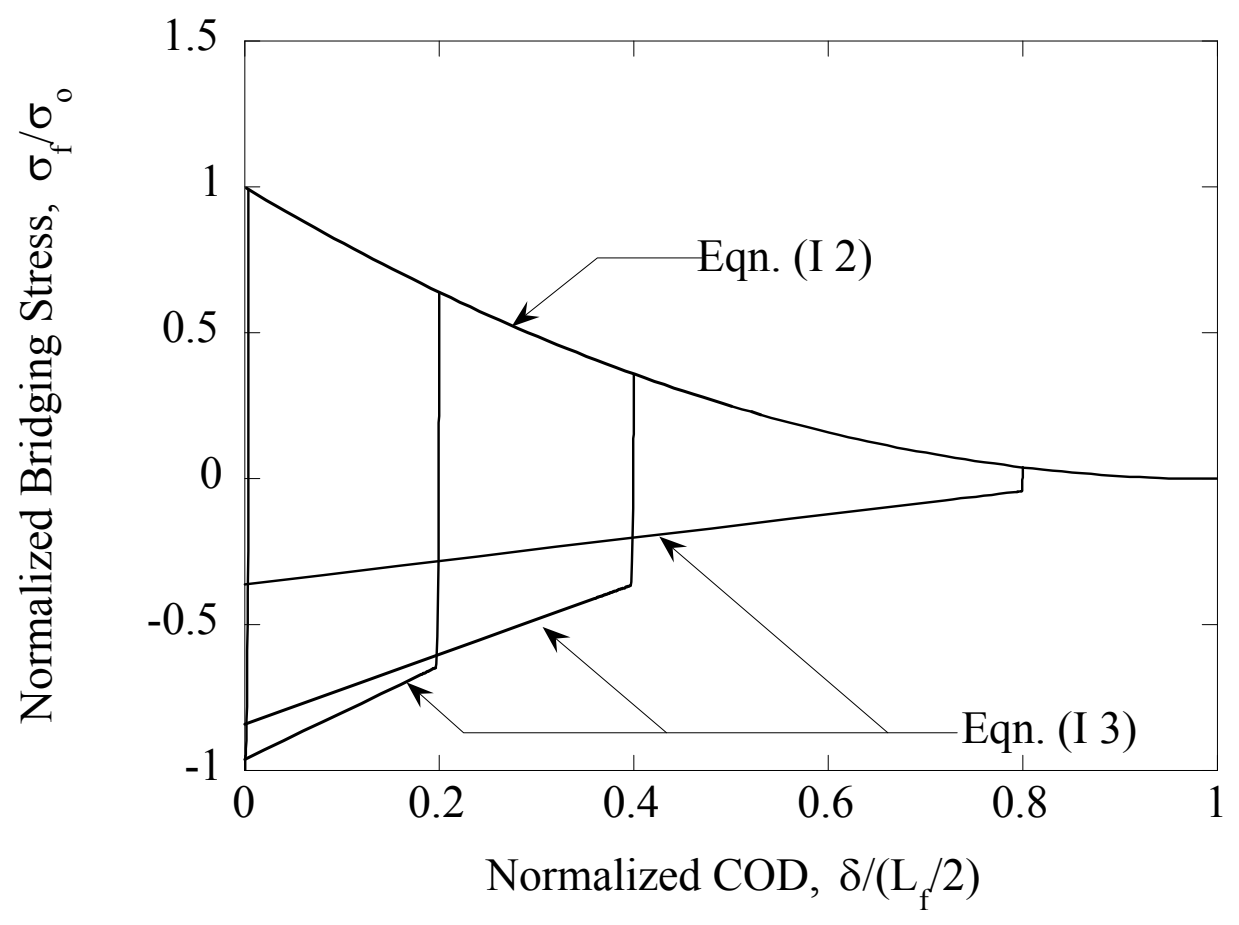

Figure 3 Fiber bridging stress-crack opening displacement (COD) relation (bridging law) for post-peak. 7 


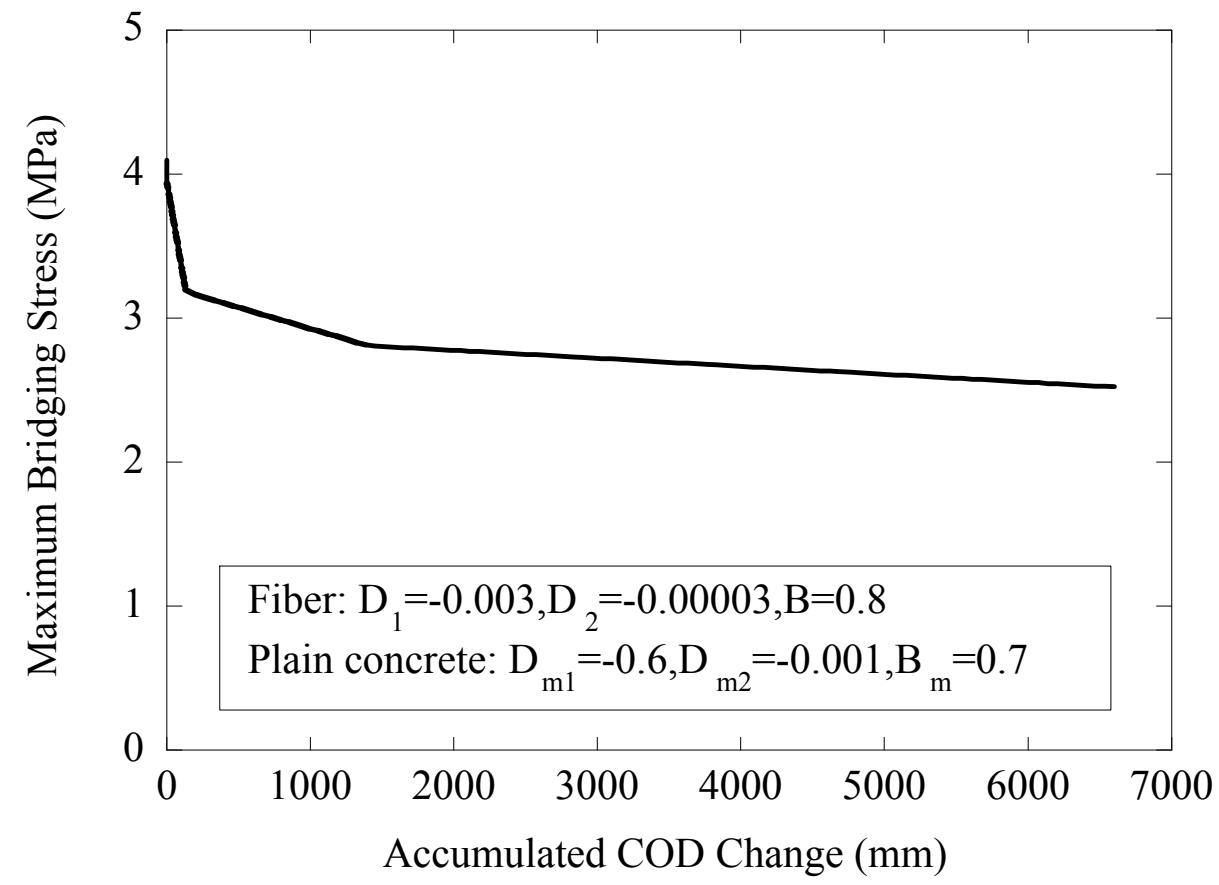

Figure 4 Crack bridging degradation assumed in the current fatigue life analysis. 

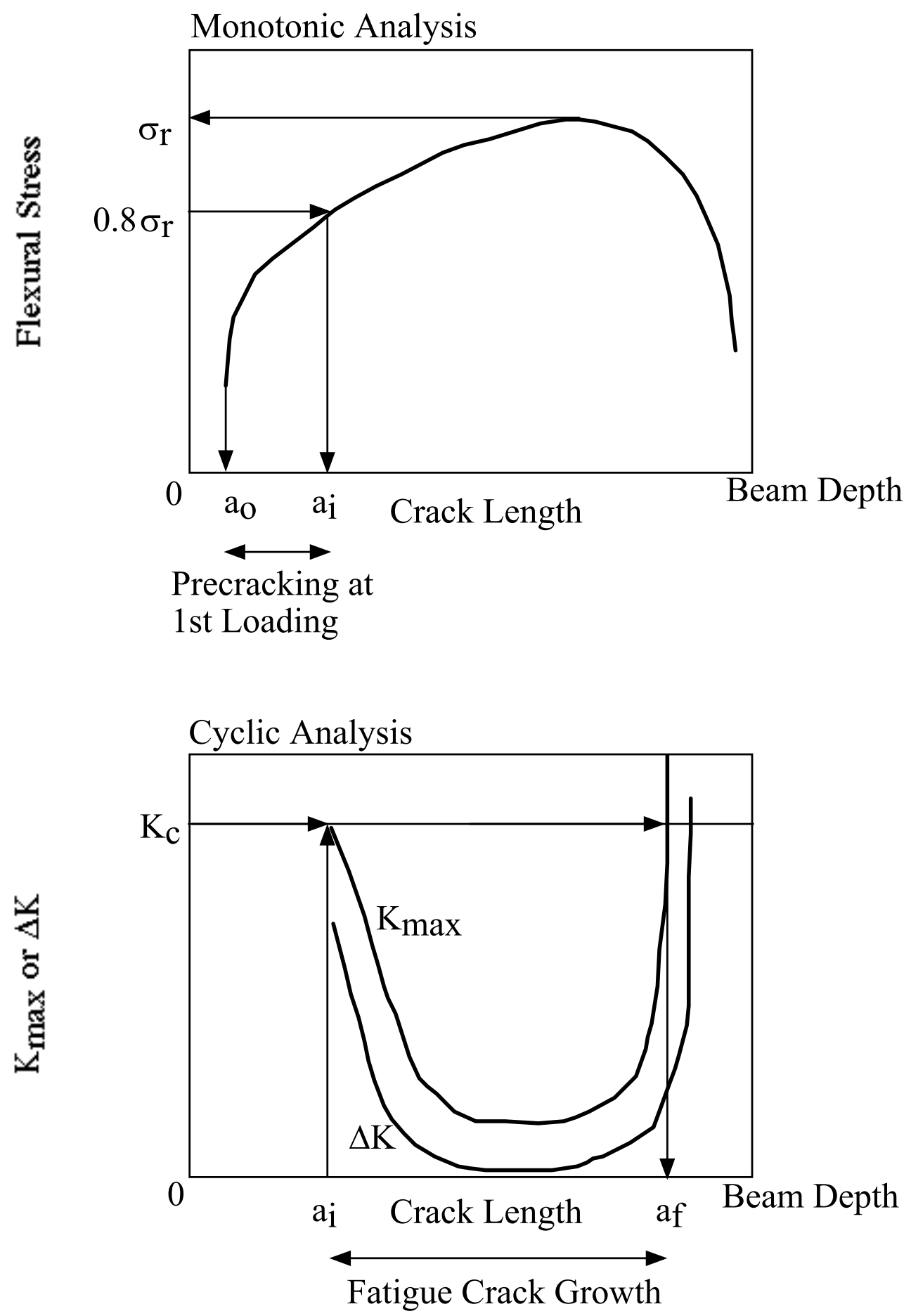

Figure 5 Flow of monotonic and cyclic analysis. 


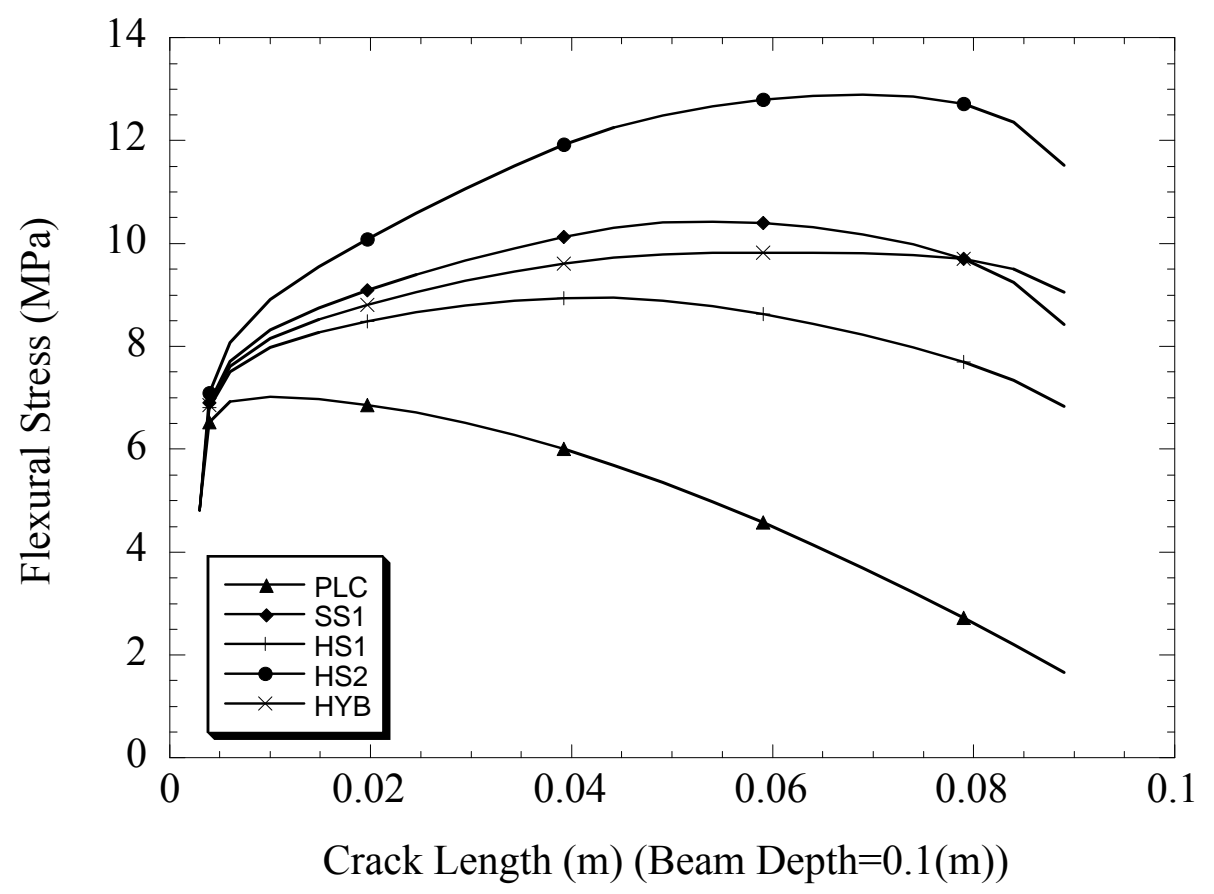

Figure 6 Monotonic analysis: crack length vs. equilibrium flexural stress. 


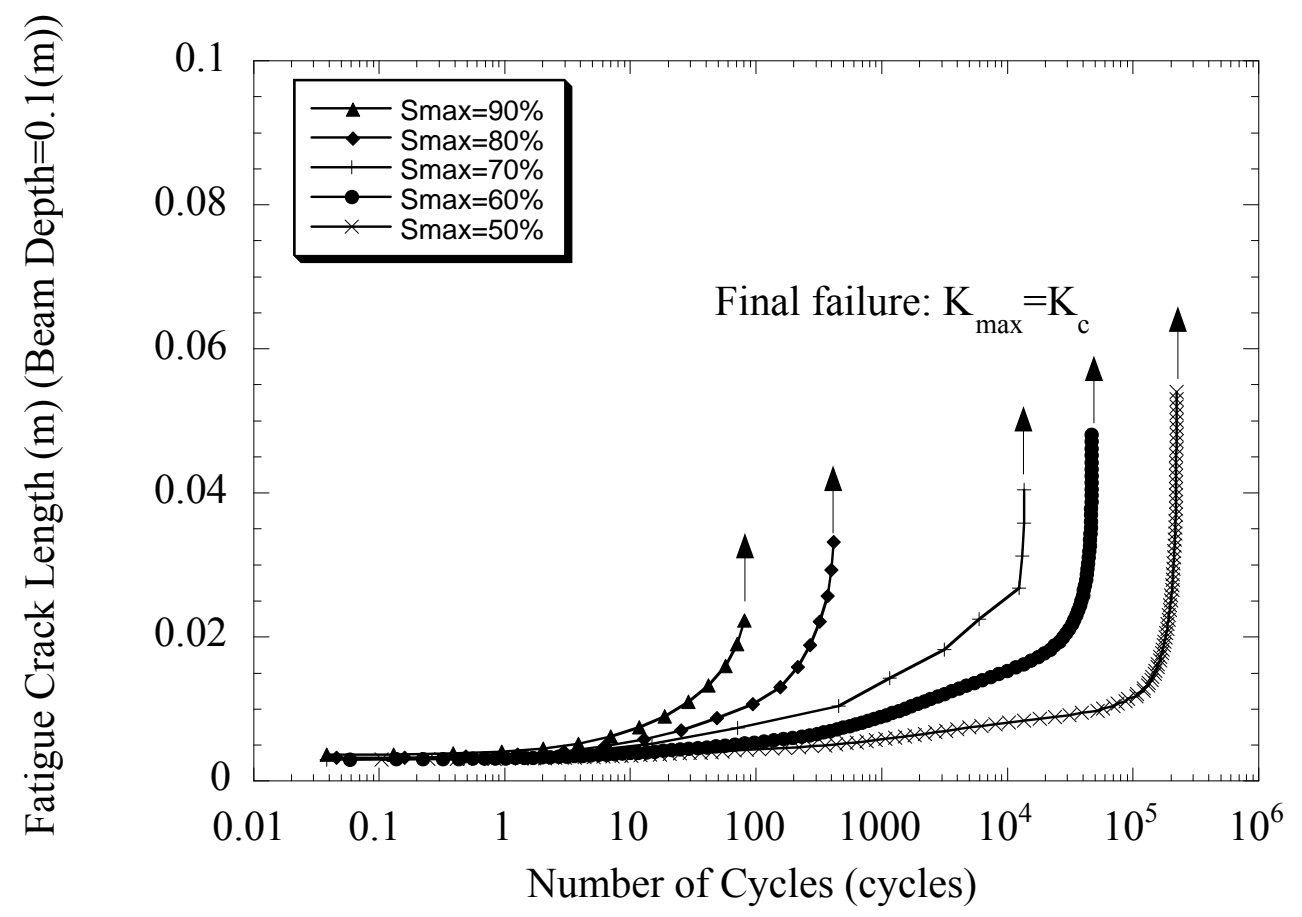

Figure 7 Fatigue crack growth in plain concrete (PLC). 


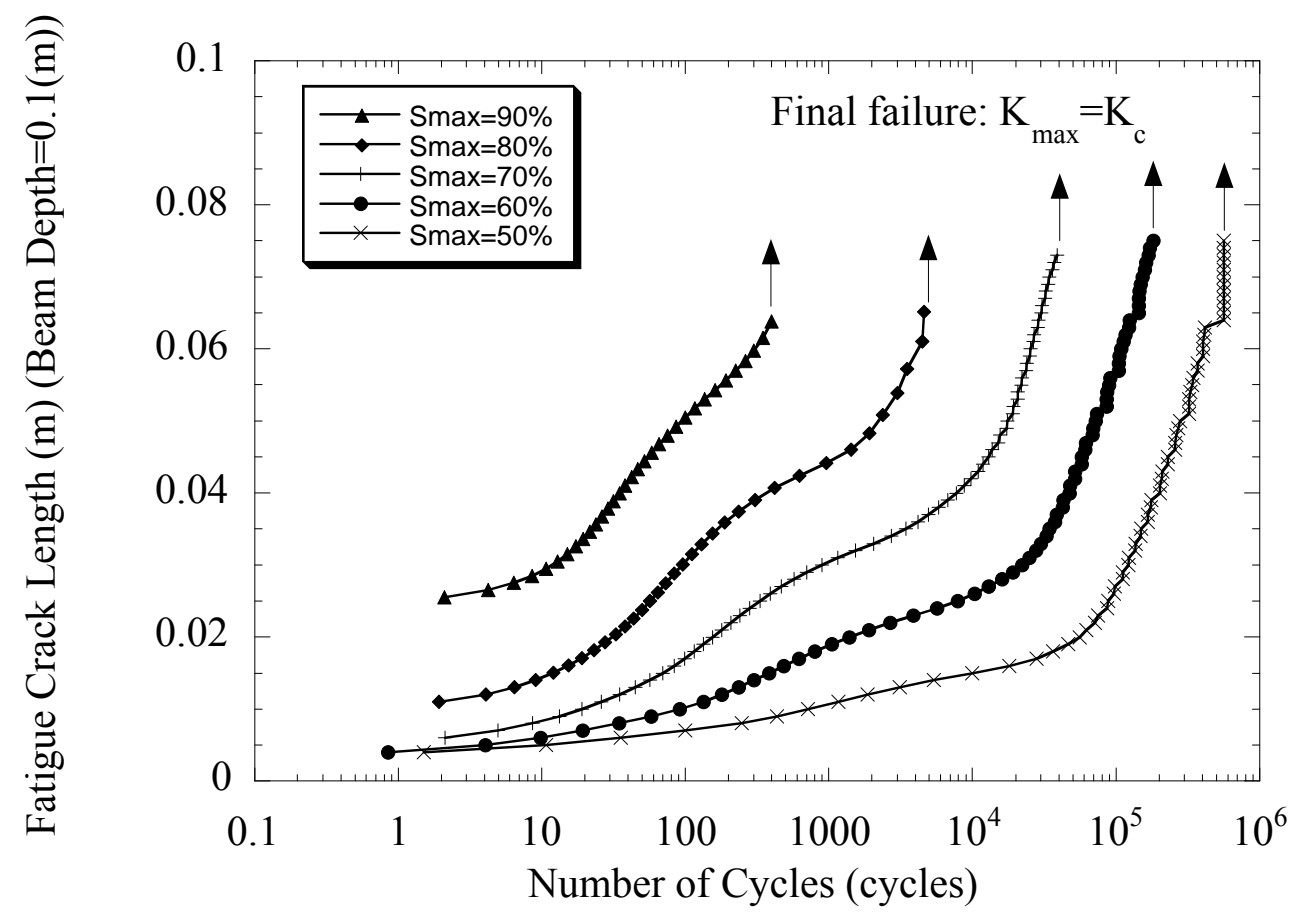

Figure 8 Fatigue crack growth in smooth steel $1 \%$ FRC (SS1). 


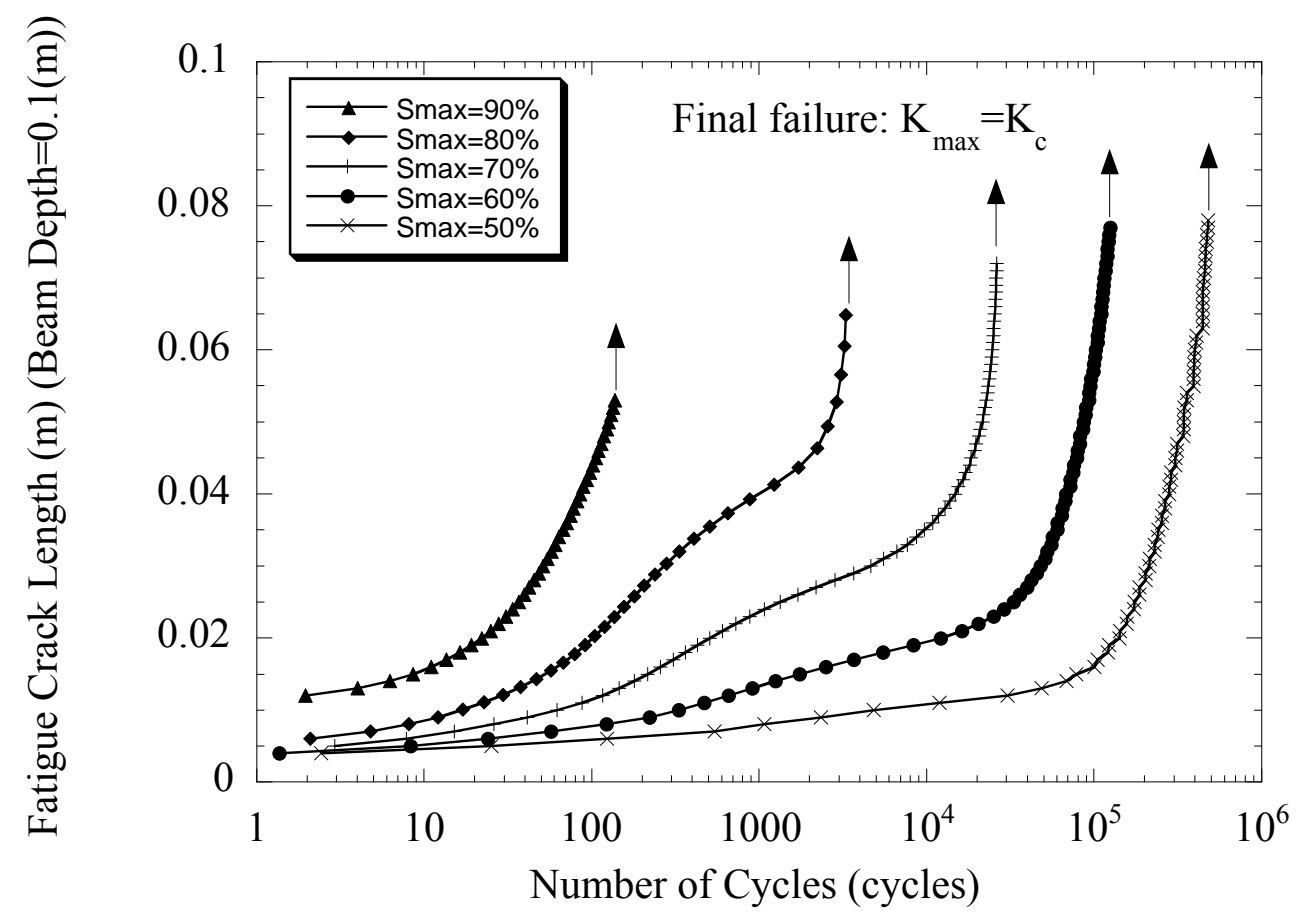

Figure 9 Fatigue crack growth in hooked-end steel $1 \%$ FRC (HS1). 


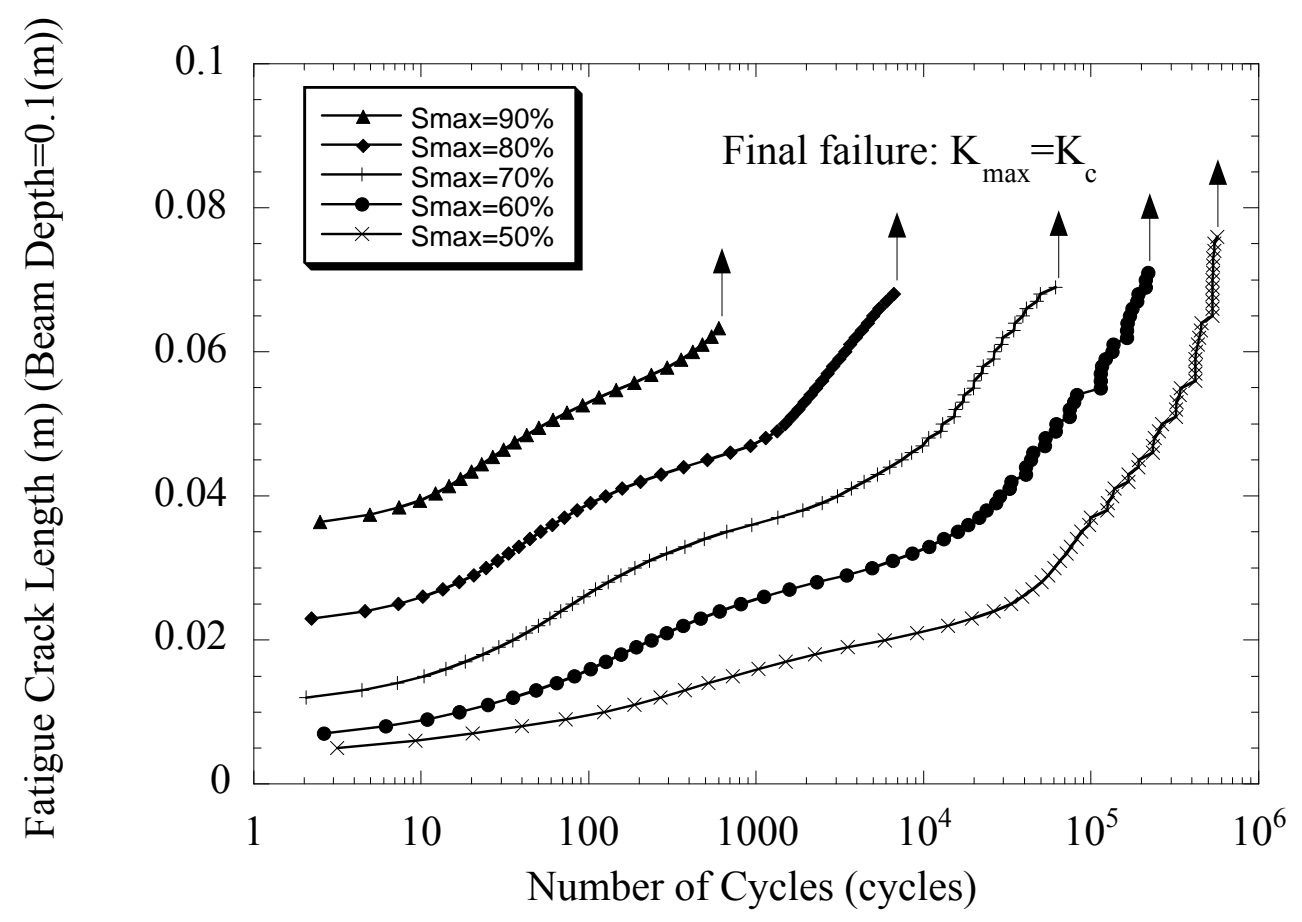

Figure 10 Fatigue crack growth in hooked-end steel $2 \%$ FRC (HS2). 


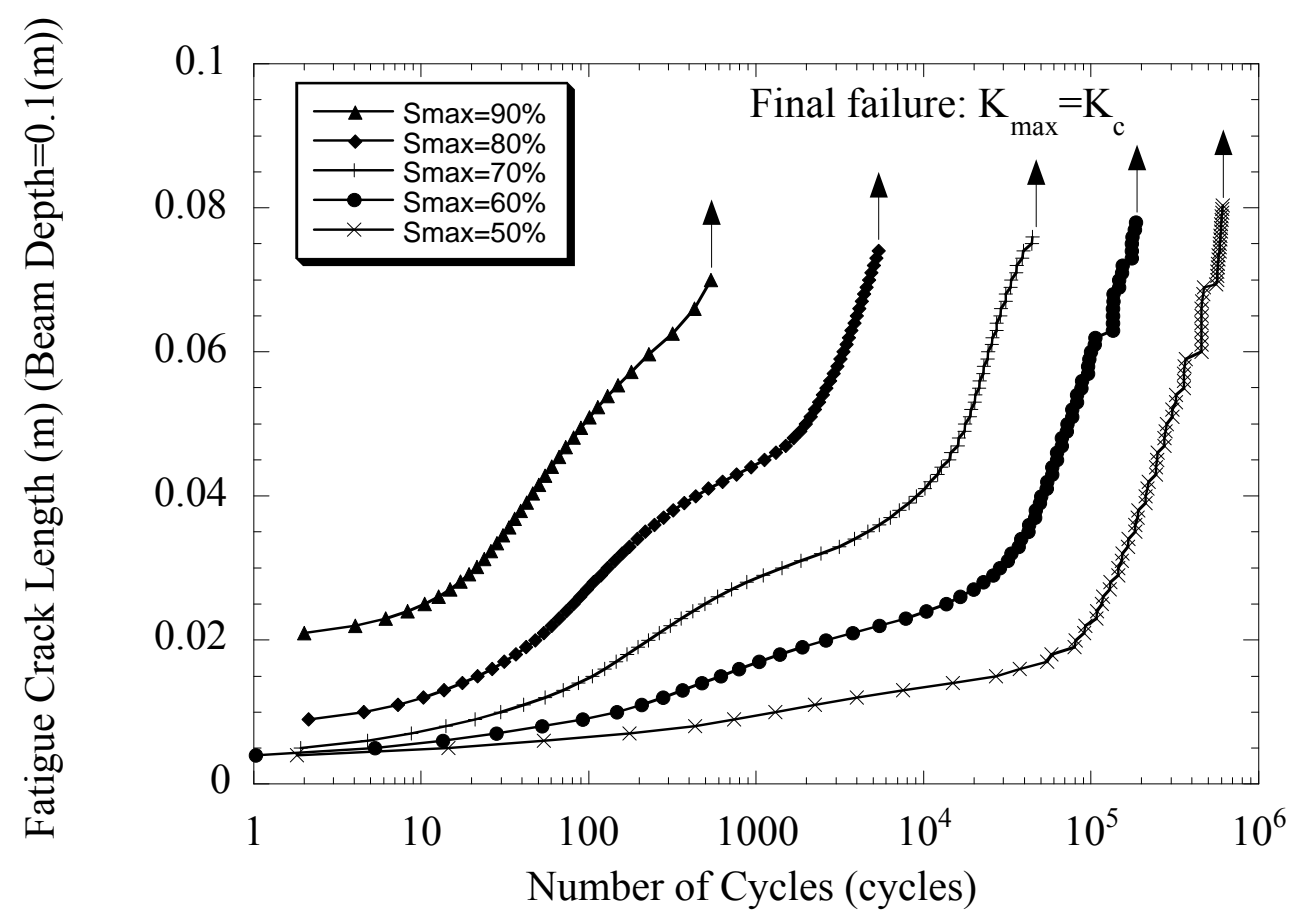

Figure 11 Fatigue crack growth in hooked-end steel $1 \%+$ polypropylene $1 \%$ FRC (HYB). 


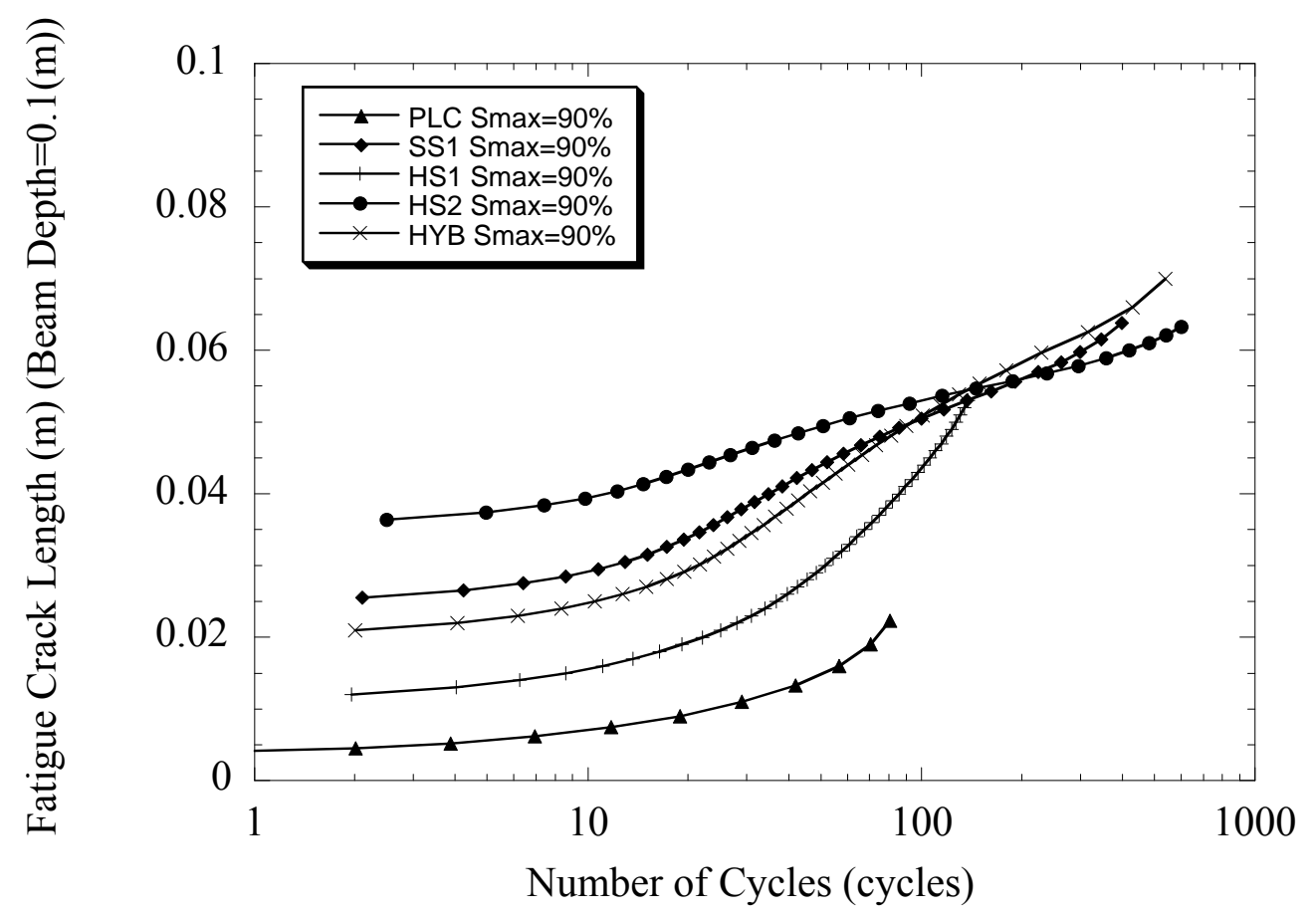

Figure 12 Fatigue crack growth behavior of plain concrete and four FRCs under $\mathrm{S}_{\max }=$ $90 \%$ and $\mathrm{R}=0.2$. 


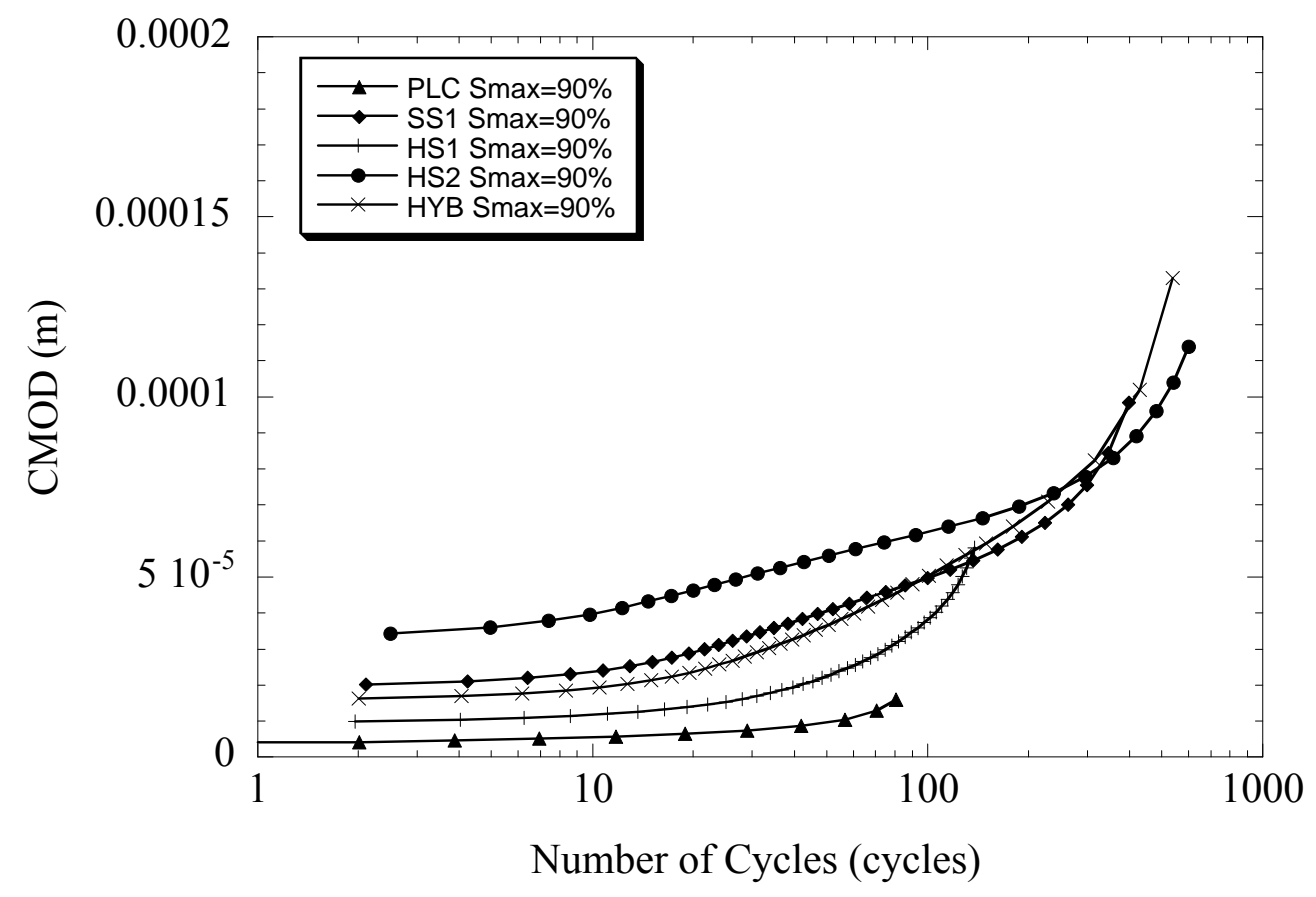

Figure 13 CMOD behavior of plain concrete and four FRCs under $\mathrm{S}_{\max }=90 \%$ and $\mathrm{R}=0.2$. 


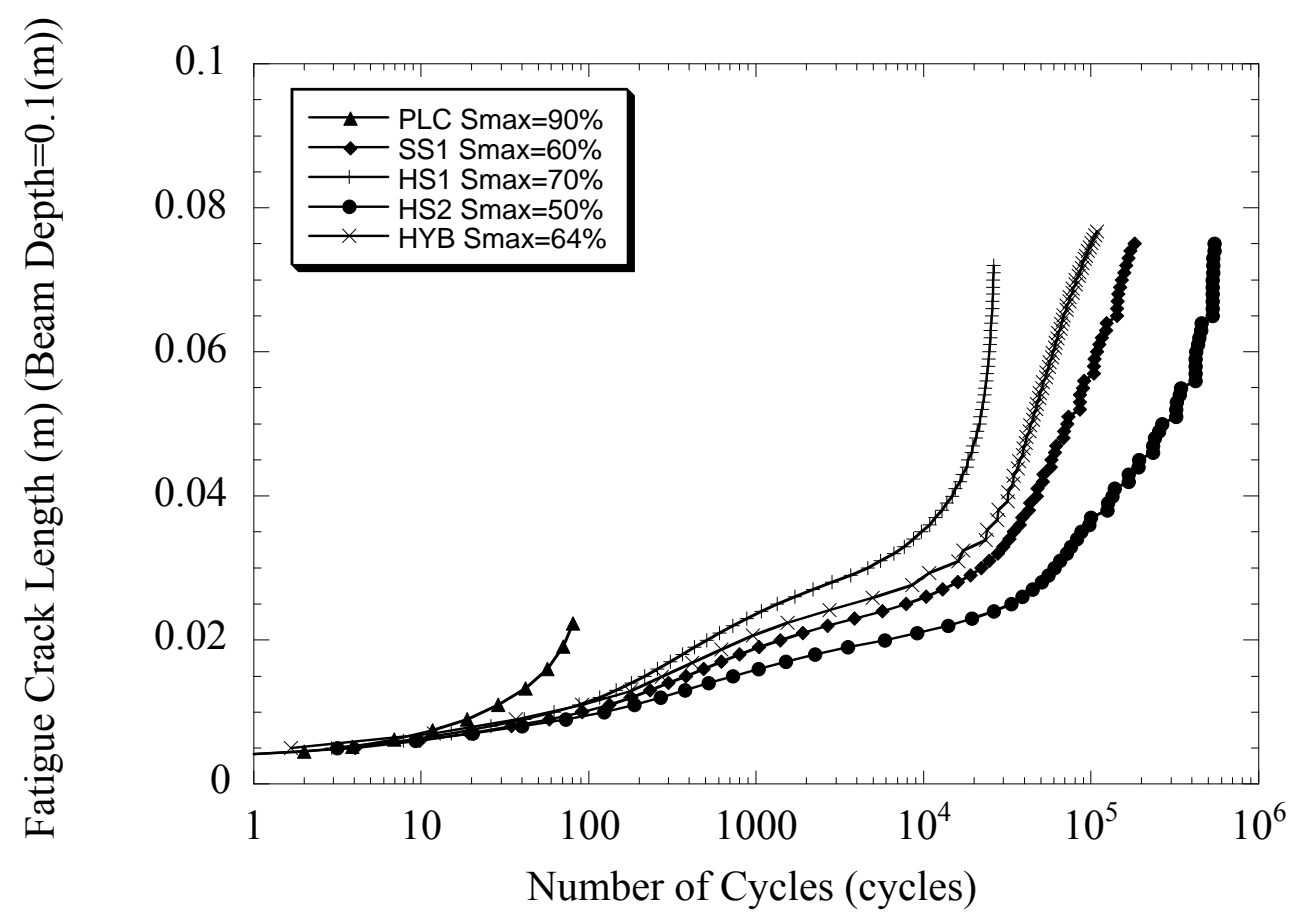

Figure 14 Fatigue crack growth behavior of plain concrete and four FRCs under $\Delta \sigma=5.0$ $\mathrm{MPa}$ and $\mathrm{R}=0.2$. 


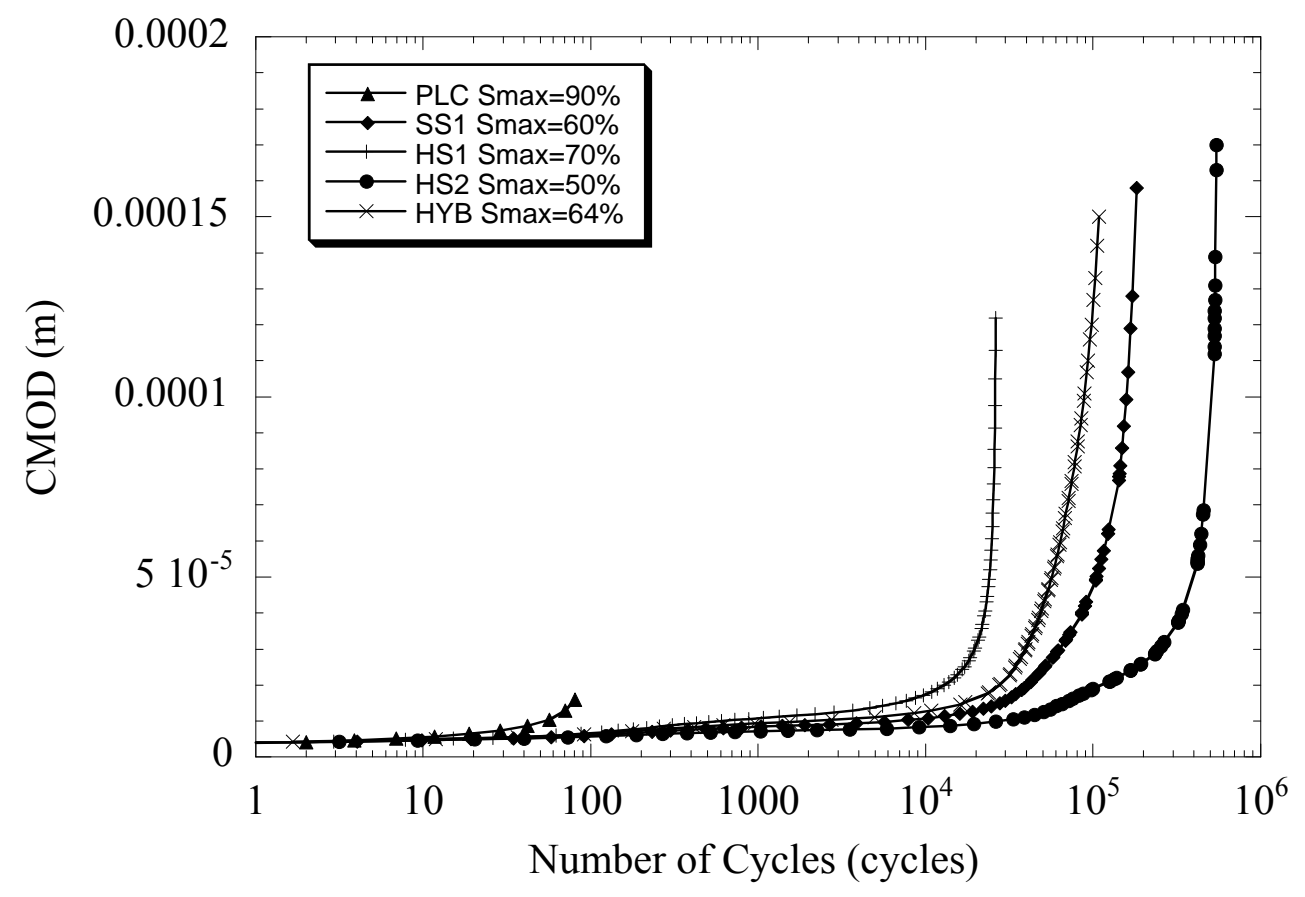

Figure $15 \mathrm{CMOD}$ behavior of plain concrete and four FRCs under $\Delta \sigma=5.0 \mathrm{MPa}$ and $\mathrm{R}=$ 0.2 . 


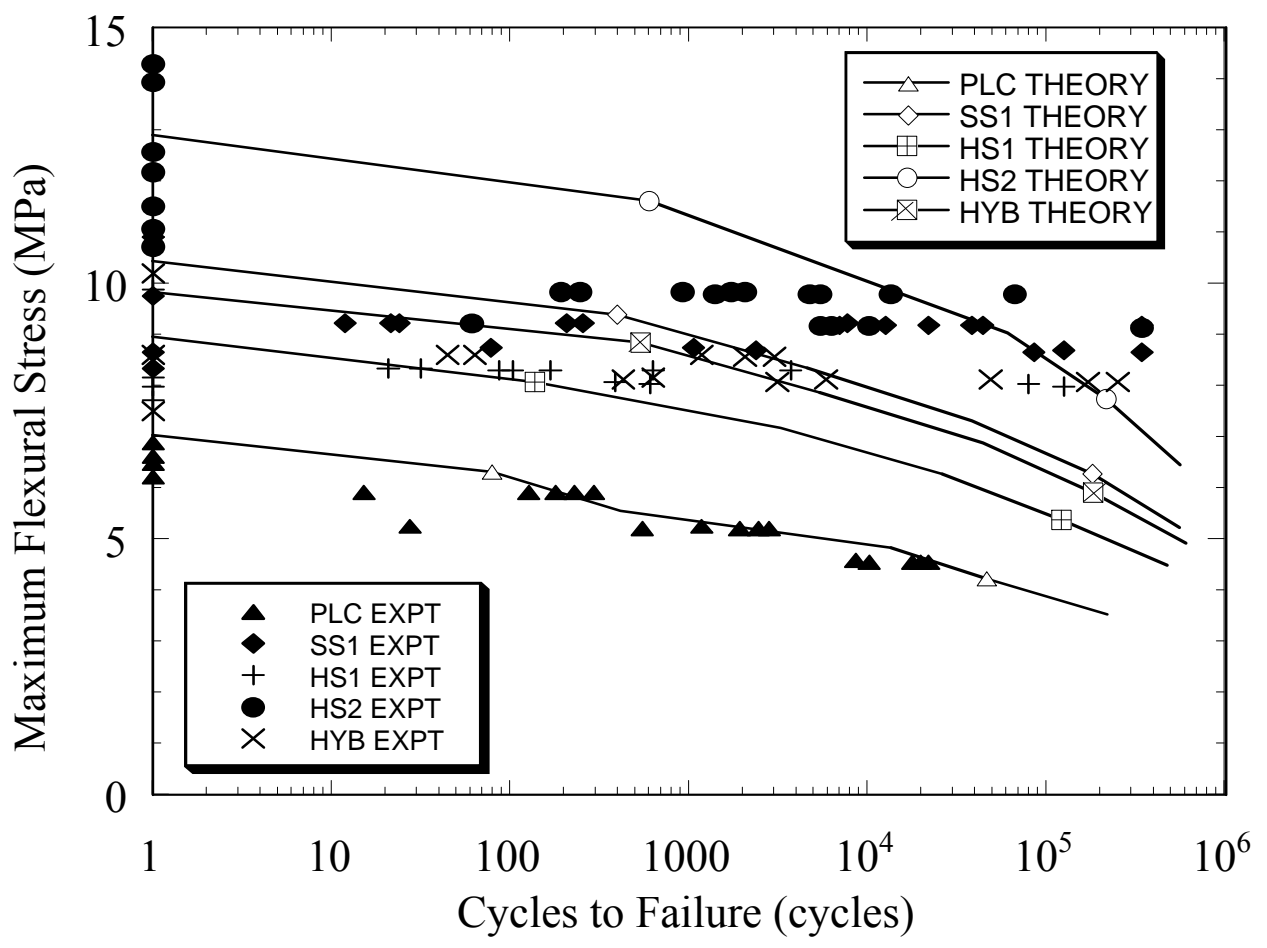

Figure 16 Theoretical S-N diagram and experimental data 25 of plain concrete and four FRCs. 


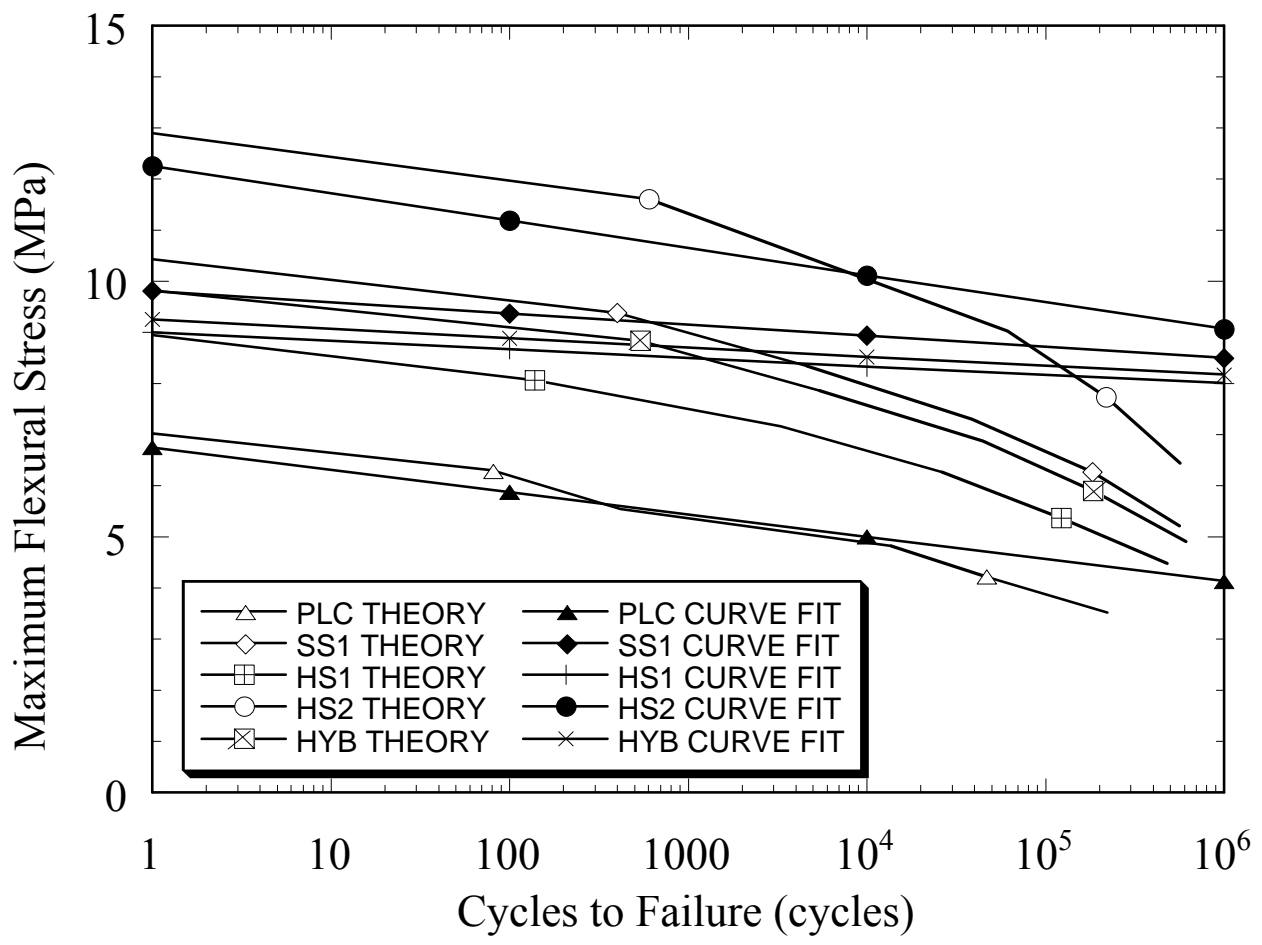

Figure 17 Theoretical S-N diagram and curve fit to experimental data 25 of plain concrete and four FRCs. 